\title{
Skeletal muscle insulin resistance: role of mitochondria and other ROS sources
}

\author{
Sergio Di Meo, Susanna lossa and Paola Venditti \\ Department of Biology, University of Naples 'Federico II', Naples, Italy
}

Correspondence should be addressed to S Di Meo

Email

sergio.dimeo@unina.it

\begin{abstract}
At present, obesity is one of the most important public health problems in the world because it causes several diseases and reduces life expectancy. Although it is well known that insulin resistance plays a pivotal role in the development of type 2 diabetes mellitus (the more frequent disease in obese people) the link between obesity and insulin resistance is yet a matter of debate. One of the most deleterious effects of obesity is the deposition of lipids in non-adipose tissues when the capacity of adipose tissue is overwhelmed. During the last decade, reduced mitochondrial function has been considered as an important contributor to 'toxic' lipid metabolite accumulation and consequent insulin resistance. More recent reports suggest that mitochondrial dysfunction is not an early event in the development of insulin resistance, but rather a complication of the hyperlipidemia-induced reactive oxygen species (ROS) production in skeletal muscle, which might promote mitochondrial alterations, lipid accumulation and inhibition of insulin action. Here, we review the literature dealing with the mitochondria-centered mechanisms proposed to explain the onset of obesity-linked IR in skeletal muscle. We conclude that the different pathways leading to insulin resistance may act synergistically because ROS production by mitochondria and other sources can result in mitochondrial dysfunction, which in turn can further increase ROS production leading to the establishment of a harmful positive feedback loop.
\end{abstract}

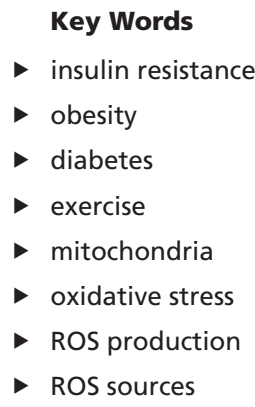

Journal of Endocrinology (2017) 233, R15-R42

\section{Introduction}

In recent years, the observation that insulin resistance (IR) and type 2 diabetes mellitus (T2DM) are growing dramatically all over the world has stimulated the research on such metabolic disorders and their possible therapy. At present, it is well established that the high incidence of IR is in great part due to the global epidemic of obesity (Amati et al. 2009), a medical condition with a chronic imbalance between energy intake and energy expenditure, described as excess body weight in the form of fat. Epidemiological studies show that the mean weight of the population is increasing and that the prevalence of overweight and obesity in adults and children is rapidly rising, especially in urban populations.

It is well known that there are several factors contributing to the increased risk of developing obesity including inactivity, overeating, higher age, smoking cigarettes, ethnicity and inherited predisposition to obesity.

It is also well established that skeletal muscle plays a central role in the whole body IR (Zierath et al. 2000). 
However, the mechanisms underlying the relationship between obesity and skeletal muscle IR are yet a matter of debate. The prevailing theory is based on the inability of adipose tissue to store the excess energy, which results in an elevated outflow of free fatty acids (FFA) from fat depots at other tissues including skeletal muscle (Sethi \& Vidal-Puig 2007). The excessive lipid content within this tissue causes metabolic dysregulation, including IR. The theory also suggests that mitochondria are key players in the IR development, but there are different views about the mechanisms by which mitochondria contribute to IR pathogenesis. It has been proposed that a decrease in mitochondrial fatty acid oxidation caused by mitochondrial dysfunction and/or reduced mitochondrial content leads to the accumulation of increased levels of intracellular fatty acyl-CoA and diacylglycerol, which interfere with the insulin signaling (Lowell \& Shulman 2005). It has also been proposed that the development of IR in skeletal muscle is due to an enhancement in mitochondrial oxidant production in response to excess fuel relative to demand, which results, through different pathways, in decreased insulin signaling and glucose transport (Rindler et al. 2013).

It is worth noting that even though in any case a pivotal role in the obesity-linked IR is assigned to mitochondria (Lark et al. 2012), recent researches propose the involvement of other cellular organelles and enzymes (Newsholme et al. 2007).

The purpose of this review is to examine the literature examining how the mitochondria might act as a contributory factor to skeletal muscle IR describing possible cellular and molecular mechanisms. Another not secondary purpose of the review is to find a way, if any, to reconcile the different views on the role of mitochondria in IR development.

\section{Obesity}

In the 21st century, obesity is one of the most important public health problems in the world. It is a chronic disease in the same sense as hypertension and atherosclerosis. The etiology of obesity is the imbalance between the energy ingested with food and the energy expended. The excess energy is stored in fat cells that enlarge and/or increase in number. Although the fact that overweight people likely die young is long known, only recently the mechanisms by which obesity causes ill-health and reduces life expectancy have been understood. The disease that is increased by the greatest degree in obese people, compared with lean ones, is T2DM. This condition usually develops in middle age and is associated with increased liability to cardiovascular disorders, which may lead to damage to the eyes, kidneys, peripheral nerves and circulation.

T2DM is characterized by excessively high plasma glucose concentrations, brought on by an imbalance between glucose and its main regulator, insulin. Although the primary defect in the pathogenesis of T2DM is not known, the manifestation of this progressive metabolic disorder is probably due to a combination of genetic and environmental factors (Leahy 2005). Common environmental influences include a high-fat highcalorie diet, lack of physical activity and obesity. Genetic predisposition can lead to defects in $\beta$-cell function, glucose sensing, insulin signaling and appetite regulation.

Although identifying the mechanisms underlying T2DM is difficult, at present, it is well established that a pivotal role in its development is played by IR.

The mature adipocyte contains a single large fat droplet, which occupies most of the cell's volume and is surrounded by a thin rim of cytoplasm that lies between the droplet and the plasma membrane. The primary function of the adipocyte is to store energy in the form of triglycerides (TG) during periods of energy surplus and to mobilize these stored lipids as fatty acids when energy is required (Otto \& Lane 2005). Fatty acids are released into the blood stream and supply the peripheral tissues, especially skeletal muscle and the liver, as an energy-rich fuel.

Adipose tissue does not only store energy but also acts as an active endocrine and paracrine organ that plays a major role in the control of metabolism through secretion of a large number of biologically active molecules (Matsuzawa et al. 1999), collectively known as adipocytokines or adipokines, including plasminogen activator inhibitor-1 (PAI-1), tumor necrosis factor $\alpha$ (TNF- $\alpha$ ), resistin, leptin and adiponectin (Vettor et al. 2005).

The increase in adipose tissue mass in obesity is the result of both an increase in the number (hyperplasia) and size (hypertrophy) of fat-laden adipocytes (Otto \& Lane 2005). Although the hypertrophy of adipocytes is rapidly reduced by food deprivation, i.e. fasting, hyperplasia is resistant to change. Therefore, once an individual has experienced the obese state, the 'new' adipocytes acquired persist and are quickly refilled if energy intake exceeds expenditure.

It has been proposed that hyperplasia and hypertrophy of fat cells represent the pathological lesion of obesity (de Ferranti \& Mozaffarian 2008). Enlarged fat cells produce the clinical problems associated with

Published by Bioscientifica Ltd. 
obesity either because of the mass of the extra fat or because of the increased secretion of free fatty acids and numerous peptides from enlarged fat cells. Indeed, the dysregulated production of the adipocytokines participates in the pathogenesis of obesity-associated metabolic syndrome, even though the mechanisms by which fat accumulation leads to such a dysregulation have not yet been elucidated. Increased production of PAI-1 and TNF- $\alpha$ from accumulated fat contributes to the development of thrombosis (Shimomura et al. 1996) and IR (Hotamisligil et al. 1993), respectively. In contrast, adiponectin exerts insulin-sensitizing (Berg et al. 2001) and anti-atherogenic effects (Okamoto et al. 2002), and therefore, a decrease in plasma adiponectin is associated with IR and atherosclerosis. Adiponectin is believed to activate the 5'-AMP activated protein kinase (AMPK), which seems to play a role in insulin-independent glucose uptake by the muscle (Yamauchi et al. 2002).

\section{Insulin resistance}

IR is a reduction of the responses of peripheral target tissues including muscle, adipose tissue and liver to a physiological concentration of insulin, so that IR is characterized by reduced tissue insulin sensitivity and reduced glucose, lipid and protein metabolism.

IR and functional impairment of islet $\beta$ cells are the main pathological causes and hallmarks of T2DM. IR occurs before the islet $\beta$ cell damage, so that at least initially the majority of diabetes patients are noninsulin dependent and capable of producing insulin, but are only deficient in their cellular response. When pancreatic $\beta$-cells are no longer able to compensate for IR by adequately increasing insulin production, impaired glucose tolerance appears, characterized by excessive postprandial hyperglycemia (Gerich 2003). IR in skeletal muscle and abnormal pancreatic $\beta$-cell function are the earliest detectable defects preceding hyperglycemia even 10 years before diabetes is diagnosed. Multiple factors contribute to IR, and it is widely accepted that obesity, reduced physical activity and genetic alterations are the main risk factors for IR. However, the precise molecular mechanism of IR remains largely unknown.

Skeletal muscle, by virtue of its mass and high rate of insulin-stimulated glucose transport, represents an important tissue in the development of IR (Caro et al. 1989). Thus, skeletal muscle IR represents a major defect in the maintenance of normal levels of glycemia (Zierath et al. 2000) and is often accompanied by a variety of metabolic and cardiovascular abnormalities, including hypertension, dyslipidemia, T2DM and atherosclerosis (DeFronzo \& Ferrannini 1991). Because of the importance of skeletal muscle in the development of IR, many researchers focused on this tissue, and the results of their works seem to indicate that the impaired glucose uptake that characterizes skeletal muscle IR results from impaired insulin receptor signaling (Goodyear et al. 1995, Bjornholm et al. 1997, Cusi et al. 2000).

\section{Insulin action}

In normal conditions, the insulin actions are initiated by its interaction with specific receptors on the cell surface of many cell types including muscle cells, adipocytes, hepatocytes and neurons of the CNS (White \& Kahn 1994). The insulin receptor spans the plasma membrane and, upon binding with insulin, transmits inside the cell a signal, which is amplified and triggers a variety of intracellular responses promoting energy storage and inhibiting mobilization of energy reserves. Indeed, insulin activates glucose uptake by muscle cells and adipocytes, and promotes glycogen and fat synthesis in hepatic cells.

The binding of insulin to the $\alpha$-subunits of its receptor stimulates the tyrosine activity of the receptor $\beta$ subunit. This tyrosine kinase phosphorylates several intracellular proteins leading to the activation of different signaling pathways. Although the extracellular signal-regulated kinase (ERK) pathway is mainly involved in growth, the activation of phosphatidylinositol 3-kinase (PI3K) is involved in the metabolic actions of insulin (White 2002). Such actions are mediated by the insulin receptor-catalyzed phosphorylation of the insulin receptor substrates 1 and 2 (IRS1, IRS2). The tyrosine-phosphorylated IRS proteins then interact with and activate PI3K, a critical player in insulin signaling particularly with regard to glucose homeostasis (Cheatham et al. 1994). PI3K appears to facilitate the translocation to the plasma membrane of the insulin-responsive glucose transporter (GLUT4), which mostly resides within intracellular storage sites. The process plays a crucial role in insulin-mediated glucose transport into the skeletal muscle (Zisman et al. 2000), but the link between PI3K and glucose transport is not completely known. It is likely that the mechanism is mediated by the recruitment and activation of 3-phosphoinositidedependent kinases (PDK), and subsequent PDK-dependent phosphorylation of a serine/threonine kinase, protein kinase B (PKB/AKT) (Kohn et al. 1996). Although AKT has several substrates, including atypical protein kinase $\mathrm{C}$ (PKC) isoforms and glycogen synthase kinase 3 (GSK3),

Published by Bioscientifica Ltd 
another substrate of $160 \mathrm{kDa}$ (AS160), has emerged as an additional molecule important in the activation of glucose transport in muscle. AS160 is a protein that in activated form prevents GLUT4 translocation to the membrane. It is phosphorylated and inactivated by AKT so that, by AS160 inhibition, insulin promotes the GLUT4 translocation from inner vesicles, promoting fusion to the plasma membrane and consequently glucose uptake (Sakamoto \& Holman 2008).

Some works have provided evidence that an atypical

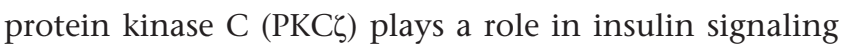
and glucose transport activation. PKC $\zeta$ is activated by insulin in a PI3K-dependent manner in L6 muscle cells (Bandyopadhyay et al. 1997). The use of PKC inhibitors and inactive mutants has demonstrated that this kinase is required for full insulin stimulation of glucose transport. Moreover, insulin induces the phosphorylation of PKC by PDK1 and the relocalization of PKC $\zeta$ to GLUT4 vesicles in rat adipocytes (Bandyopadhyay et al. 1999). These studies indicate that there may be a requirement for the activation of both PKB and PKC $\zeta$ for GLUT4 translocation and subsequent glucose transport stimulation. However, a complete understanding of the mechanisms by which PKC $\zeta$ interacts with other components of the signaling pathway remains to be achieved.

It is worth noting that to propagate the tyrosine kinase signal, as well as signaling through downstream protein and phospholipid kinases, insulin binding also initiates the deactivation of members of the family of the protein tyrosine phosphatases, such as protein tyrosine phosphatase 1B (PTP1B) and phosphatase and tensin homolog (PTEN), that under resting cellular conditions, have an activity, which exceeds kinase activity and inhibit insulin signaling (Elchebly et al. 1999, Wijesekara et al. 2005) (Fig. 1, upper panel).

\section{Impairment of insulin signaling in insulin resistance}

Subjects with obesity (Goodyear et al. 1995) and subjects with T2DM (Bjornholm et al. 1997) exhibit reduced IRS-1 tyrosine phosphorylation and reduced PI3K activity compared with their respective controls. The reduction in tyrosine phosphorylation of IRS-1 and IRS- 2 has been related to their increased serine/threonine phosphorylation (Paz et al. 1997). Proposed IRS serine/ threonine kinases include inhibitor kappa B kinase (IKK) (Gao et al. 2002), c-Jun amino-terminal kinases (JNK) (Aguirre et al. 2000) and mammalian target of rapamycin (mTOR) (Li et al. 1999). As a result of IRS serine/threonine

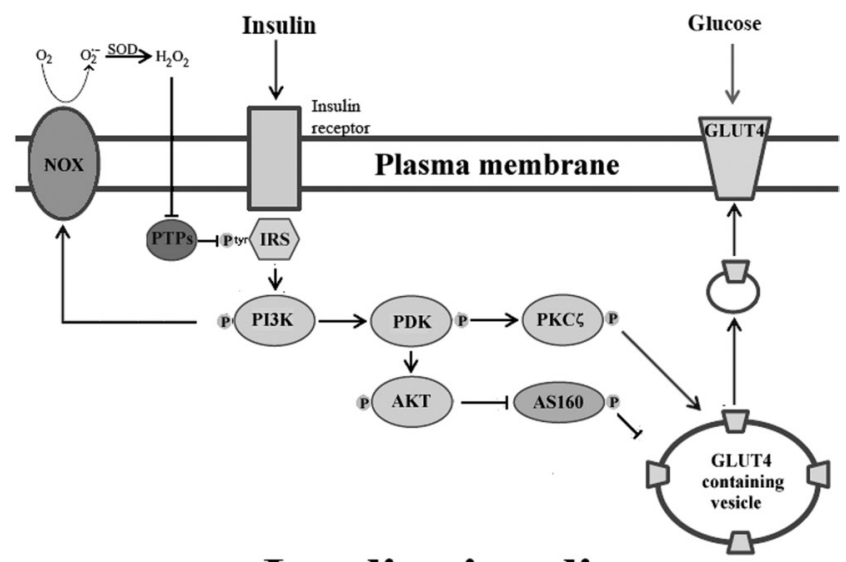

\section{Insulin signaling}

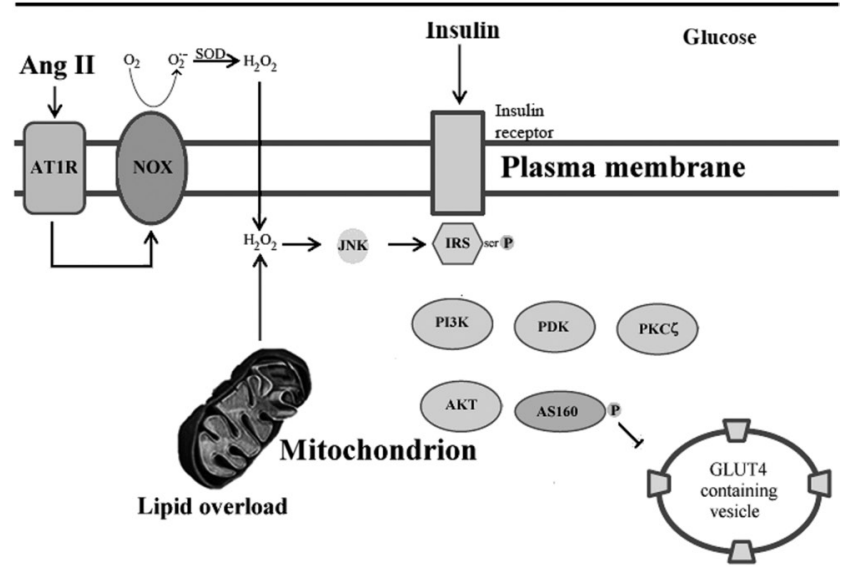

Insulin resistance

Figure 1

Schematic representation of insulin-stimulated glucose uptake in skeletal muscle and its inhibition in obese or high-fat diet-fed animals. GLUT4, glucose transporter type 4; NOX, NADPH oxidase; SOD, superoxide dismutase; Ang II, angiotensin II; AT1R, Ang II type 1 receptor; IRS, insulin receptor substrate; PI3K, phosphatidylinositol 3-kinase; PTPs, protein

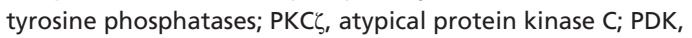

phosphoinositide-dependent kinase; Akt, protein kinase B; AS160, 160 kDa protein; JNK, c-Jun amino-terminal kinases. Reproduced, with permission, from Rindler PM, Crewe CL, Fernandes J, Kinter M \& Szweda LI (2013) Redox regulation of insulin sensitivity due to enhanced fatty acid utilization in the mitochondria. American Journal of Physiology volume 305, pages H634-H643. Copyright The American Physiological Society (APS). All rights reserved.

phosphorylation, PI3K levels are reduced with subsequent alteration of downstream effectors, i.e. decreased activity of Akt (Kim et al. 1999) and atypical PKC (Kim et al. 2003), and decreased glucose uptake, presumably due to reduced GLUT4 activity/translocation (Shulman 2000) (Fig. 1, lower panel).

It is worth noting that although considerable evidence supports the model describing a major role for IRS in IR, results inconsistent with such a model still remain, 
including the observation that the origin of IR can occur independently of IRS (Hoehn et al. 2008).

The prevalent theory on impaired insulin signaling in obesity links IR to the increase of circulating FFA. Indeed, according to this theory, one of the most deleterious effects of obesity is the deposition of lipids in non-adipose tissues. In obesity, when the capacity of visceral and subcutaneous adipose tissue is overwhelmed, circulating levels of fatty acids are markedly increased. In these conditions, other tissues are used for lipid accumulation (e.g. liver, muscle, pancreas and heart) (Sethi \& Vidal-Puig 2007). As these organs are less capable to storing lipids than adipocytes and more adversely affected, lipotoxicity may be the result culminating, in IR of muscles, liver and pancreas (Shulman 2000).

This hypothesis was supported by findings from human studies involving lipid infusion. Such a procedure increases intramyocellular lipid content (Bachmann et al. 2001, Brechtel et al. 2001) and inhibits insulin-stimulated glucose uptake in subjects who are healthy (Boden et al. 1991) and in subjects with T2DM (Boden \& Chen 1995). Thus, it was shown that the inhibition of insulinstimulated glucose uptake inversely correlated with the increased FFA levels produced by the lipid infusion (Belfort et al. 2005).

It is worth noting that, although lipid infusion is a well-documented method of producing skeletal muscle IR, it has become increasingly evident that lipid oversupply does not act alone in this process.

Because the mitochondria are the primary cellular site for fatty acid oxidation and utilization, during the last decade, reduced mitochondrial function has been considered as an important contributor to 'toxic' lipid metabolite accumulation and consequent IR.

More recently, Fisher-Wellman and coworkers (FisherWellman et al. 2014) reported that lower oxidative capacity is not a requirement for the early phases of development of IR in obesity, leaving open, however, the possibility that when mitochondrial capacity is diminished it might contribute to reduced insulin sensitivity. They also found that mitochondrial $\mathrm{H}_{2} \mathrm{O}_{2}$ emission was increased, supporting a previous report implicating oxidative stress in the pathogenesis of IR (Anderson et al. 2009).

At present, it is considered unlikely that IR is explained by a single cause. Rather, it is more likely that IR may develop as a result of multiple complementary mechanisms.

\section{Mitochondrial dysfunction in insulin resistance}

For a long time, mitochondria were mainly considered for their role in the energy production, being the sites of the oxidative phosphorylation, which couples the electron transfer from respiratory substrates to oxygen with the ATP synthesis. In such process, food-derived substances are oxidized by transfer of electrons to electron carriers such as $\mathrm{NAD}^{+}, \mathrm{FMN}$ and $\mathrm{FAD}$, which, in a series of subsequent steps, transfer electrons to the several redox centers, and finally to oxygen. Respiratory chain components involved in the electron transfer are in great part organized in four protein complexes inserted in the inner mitochondrial membrane (Navarro \& Boveris 2007). Complexes I and II transfer electrons to the lipid-soluble carrier ubiquinone, from which the electrons pass through Complex III, cytochrome c (another mobile carrier) and Complex IV, to the oxygen. The fall in electron potential energy is used to pump protons from the mitochondrial matrix to intermembrane space, thus setting up a proton-motive force (Mitchell \& Moyle 1965). Such a force drives protons back into the matrix through the mitochondrial ATP synthase leading to ATP synthesis (Walker et al. 1995).

Mitochondria are not only key actors in global energy modulation, but also are required for a wide range of functions fundamental for the cell. It is therefore not surprising that mitochondrial dysfunction is associated with a large proportion of diseases, such as neurodegenerative disorders, cardiomyopathies, metabolic syndrome, cancer and obesity (Nunnari \& Suomalainen 2012).

Mitochondrial dysfunction was first described in the context of glucose intolerance $\sim 40$ years ago (Yamada et al. 1975), but a role for mitochondria in IR emerged only from the late 1990s when studies in humans suggested the existence of mitochondrial dysfunction in obese and insulin-resistant patients (Kelley et al. 1999, Simoneau et al. 1999). From these reports the idea arose that a decrease in tissues of mitochondrial oxidative capacity, due to loss in mitochondrial content and/or function, results in insufficient lipid oxidation with the effect to exacerbate lipid excess and lead to IR.

Most of the human studies looked at the potential differences in skeletal muscle mitochondria abundance and function between insulin-sensitive, insulin-resistant and type 2 diabetes patients. Skeletal muscle mitochondria 
from type 2 diabetes patients exhibited lower activity of the respiratory chain (Kelley et al. 2002, Ritov et al. 2010), most probably arising from a reduction in the expression of genes encoding mitochondrial enzyme subunits (Mootha et al. 2003, Patti et al. 2003). Heilbronn and coworkers (Heilbronn et al. 2007) and Lefort and coworkers (Lefort et al. 2010) found a decrease in several markers of mitochondrial metabolism in IR subjects. Similar results were also obtained in overweight children (Fleischman et al. 2009) and in patients with genetic defects in insulin receptor signaling (Sleigh et al. 2011).

Peluso and coworkers (Peluso et al. 2002) analyzed skeletal muscle of obese IR individuals and of lean controls and found that mitochondrial carnitine acylcarnitine translocase was specifically decreased at translational and trasductional level, suggesting that this decrease may contribute to the elevated muscle concentrations of triglycerides, diacylglycerol and fatty acyl-coenzyme A characteristic of IR muscle. Further support to the link between intramyocellular lipids and mitochondrial function was found in insulin-resistant subjects, where lower ATP synthase was found in concomitance with elevated intramyocellular lipids compared to control subjects (Petersen et al. 2004). However, other studies observed an in vivo impairment in mitochondrial function in diabetic patients (Szendroedi et al. 2007) without accumulation of intramyocellular lipids (SchrauwenHinderling et al. 2007, Phielix et al. 2008). Ritov and coworkers (Ritov et al. 2005) compared volunteers with type 2 diabetes, obese sedentary nondiabetic volunteers and lean volunteers and found a selective decrease in the number and activity of subsarcolemmal mitochondria and suggested that this deficit may contribute to the pathogenesis of muscle insulin resistance in type 2 diabetes because of the potential importance of subsarcolemmal mitochondria for signal transduction and substrate transport. Boushel and coworkers (Boushel et al. 2007) and Holloway and coworkers (Holloway et al. 2007) claimed that blunting of mitochondrial respiration in type 2 diabetic patients or obese women, respectively, can be attributed to lower mitochondrial content, whereas mitochondrial function was normal. Young, lean, insulinresistant offspring of type 2 diabetic patients exhibited lower rates of muscle mitochondrial substrate oxidation compared to insulin-sensitive control subjects, and the authors hypothesized that insulin resistance in skeletal muscle of insulin-resistant offspring is associated with dysregulation of intramyocellular fatty acid metabolism, possibly because of an inherited defect in the activity of mitochondrial oxidative phosphorylation (Befroy et al. 2007). Because high-fat diet can result in obesity and T2DM, which are characterized by reduced mitochondrial mass and function, it was possible to hypothesize that high-fat diet is able to affect the expression of genes involved in mitochondrial biogenesis. To test this hypothesis, Sparks and coworkers (Sparks et al. 2005) studied skeletal muscles from insulin-sensitive healthy men and mice fed an isoenergetic high-fat diet for 3 days and 3 weeks, respectively. They found a downregulation of genes involved in oxidative phosphorylation and mitochondrial biogenesis and suggested that these changes that mimic those observed in diabetes and insulin resistance (Kelley et al. 2002, Mootha et al. 2003, Patti et al. 2003, Heilbronn et al. 2007, Lefort et al. 2010, Ritov et al . 2010), if sustained, might result in mitochondrial dysfunction in the prediabetic/insulin-resistant state. However, longer-term (28 days) overfeeding studies on non-obese sedentary men failed to support such an idea because the levels of proteins regulating mitochondrial biogenesis or determining oxidative capacity, which were increased at day 3, returned to basal at day 28 (Samocha-Bonet et al. 2012).

All the previously mentioned human studies consistently show that in vivo mitochondrial function is reduced in insulin-resistant subjects and/or type 2 diabetic patients. This mitochondrial impairment could contribute to the onset of insulin resistance by favoring lipid accumulation and because decreased ATP is available for membrane transports and signal transduction pathways. Although the previously cited studies all converge on the idea that mitochondrial dysfunction is a key feature of insulin-resistant muscle in men, some studies found no such correlation (De Feyter et al. 2008a,b, Karakelides et al. 2010, Samjoo et al. 2013).

Taken together, studies on men are mainly consistent with the association between insulin resistance and mitochondrial impairment, although in general, they do not discriminate between cause and effect. In addition, in human studies, it is difficult to control parameters such as energy intake, quality of the diet and level of activity.

Many studies have also been carried out in animal models of obesity and diabetes, mainly rats and mice. The results obtained in these animal models are mostly in agreement with those obtained in human studies. The most used protocol to induce insulin resistance is overfeeding with high-fat/high-sugar diets in rats (Chanseaume et al. 2006, Gomes et al. 2012, Crescenzo et al. 2013, Warren et al. 2014) or 
in mice (de Wilde et al. 2008, Shelley et al. 2009, Yuzefovych et al. 2013), however, models of genetic obesity were also used (Holmström et al. 2012). However, other observations report discrepant results, showing that high-fat feeding in rats was associated with no variation (Atgié et al. 1993, De Feyter et al. 2008a,b) or even a higher mitochondrial capacity (Hancock et al. 2008), and IR could be related to incomplete intramitochondrial $\beta$-oxidation (Koves et al. 2008). Several studies show that insulin resistance arises when mitochondrial function is unaffected or even improved (Turner et al. 2007, Hoeks et al. 2008, Ara et al. 2011, Boudina et al. 2012), or conversely that impaired mitochondrial functioning alone does not cause insulin resistance (Wredenberg et al. 2006). These latter findings data seem to indicate that, at least in rodents, consumption of high-fat diet is not always accompanied by mitochondrial dysfunction, but rather leads to improved mitochondrial oxidative capacity and/or biogenesis (Gómez-Pérez et al. 2012, Wessels et al. 2015), even in the presence of IR. The duration of high-fat feeding also seems to differently affect mitochondrial function in skeletal muscle. In fact, oxidative phosphorylation was found increased after short-term (2-3 weeks) dietary treatment, but decreased after long-term treatment (Chanseaume et al. 2007, Laurent et al. 2007, Bonnard et al. 2008).

An intriguing hypothesis proposed by several authors is that insulin resistance develops when mitochondrial dysfunction and the following inability to oxidize fatty acids takes place in conjunction with an increase in lipid flux to skeletal muscle (Chow et al. 2010). The above hypothesis is supported by the observation that the exposure to saturated fatty acids of isolated mitochondria (Abdul-Ghani et al. 2008) or cells (Hirabara et al. 2010, Jheng et al. 2012, Yang et al. 2012, Teodoro et al. 2014) clearly elicits mitochondrial dysfunction, which in the cells is accompanied by IR. However, in more complex systems, such as in men and experimental animal models, the link between plasma NEFA delivery to skeletal muscle, mitochondrial impairment and insulin resistance is less strong. Acute elevation in plasma NEFA by fasting in men was found to induce mitochondrial dysfunction in skeletal muscle in the absence of insulin resistance (Hoeks et al. 2010), whereas acute infusion of FFA+insulin in rats blunted insulin signaling in skeletal muscle without any effect on mitochondrial function (Barazzoni et al. 2012). Taken together, the previously mentioned results are in line with the idea that mitochondrial dysfunction may arise in consequence of muscular fat accumulation and could in turn elicit insulin resistance.

The cellular capacity of lipid oxidation is affected by mitochondrial number, mitochondrial activity and mitochondrial degree of coupling between oxidation of fuels and ATP synthesis. Moreover, substrate oxidation rate is strictly linked to ATP turnover (Boveris et al. 2000), so that, in resting skeletal muscle, changes in mitochondrial degree of coupling, but not changes in organelle number and/or activity, would affect the amount of oxidized fuels, even if ATP turnover does not vary. In fact, the mitochondrial coupling efficiency determines how many calories are used to perform work (ATP) or to produce heat. To our knowledge, few data on the regulation of mitochondrial degree of coupling in skeletal muscle in response to obesity-induced insulin resistance are available. An increased degree of coupling in skeletal muscle mitochondria has been found after short-term dietary treatment with lipid-rich diet, when insulin resistance is not yet elicited (Crescenzo et al. 2014, 2015). Therefore, these results could be consistent with a role for mitochondrial impairment in the onset of insulin resistance. When mitochondria are more coupled, less fuels are oxidized to synthesize the same amount of ATP. As during high-fat feeding there is an increased lipid supply to skeletal muscle (Crescenzo et al. 2015), lipid supply would exceed lipid burning, leading to ectopic fat deposition. Interestingly, after 7 weeks of lipid-rich diet, insulin resistance develops, but the modification of mitochondrial degree of coupling disappears (Lionetti et al. 2007), probably due to highfat-induced alterations in lipid composition of the mitochondrial membranes, an important determinant of mitochondrial efficiency (Jastroch et al. 2010). An increased mitochondrial degree of coupling has also been found when a lipid-rich, fructose-rich diet was given to rats for 2 weeks, a period that also elicits insulin resistance (Crescenzo et al. 2015). By comparing the two sets of results, it can be hypothesized that, at least in this model of insulin resistance, the increased mitochondrial degree of coupling could contribute to elicit insulin resistance. Accordingly, the amount of skeletal muscle ceramides, which are responsible for the impairment of insulin signaling (Coen \& Goodpaster 2012), is increased with lipid-rich diet and is even higher with lipid-rich, fructoserich diet (Crescenzo et al. 2015), probably reaching a threshold level that partly blocks the insulin transduction pathway. 


\section{Oxidative stress in insulin resistance}

The oxygen utilization by aerobic organisms results in the production of chemical species possessing one or more unpaired electrons, called free radicals, which can initiate chain reactions eventually leading to cell structural and functional alterations (Valko et al. 2007). Indeed, various processes occurring in mitochondria and other cellular sites, including cytosol, endoplasmic reticulum, peroxisomes and lysosomes (Venditti et al. 2015, Di Meo et al. 2016), lead to partial oxygen reduction and formation of free radicals and other reactive oxygen species (ROS). ROS include superoxide anion radical $\left(\mathrm{O}_{2}{ }^{-}\right)$, hydrogen peroxide $\left(\mathrm{H}_{2} \mathrm{O}_{2}\right)$ and hydroxyl radical $(\cdot \mathrm{OH})$. Of these, $\cdot{ }^{\circ} \mathrm{OH}$ is the most reactive and can be generated by the reaction of $\mathrm{H}_{2} \mathrm{O}_{2}$ with iron (or copper) ions (the Fenton reaction). $\cdot \mathrm{OH}$ can attack polyunsaturated fatty acids, causing a loss of biomembrane integrity, proteins and enzymes, damaging functional properties and nucleic acids, giving rise to mutations and ultimately cell senescence or death (Halliwell \& Gutteridge 2015).

In most (if not all) mammalian cells, another free radical, containing nitrogen and named nitric oxide $(\mathrm{NO} \cdot)$, is synthesized from L-arginine by NO synthases (NOS) (Knowles \& Moncada 1994). NO• is relatively unreactive, but may be converted to a number of more reactive derivatives, known collectively as reactive nitrogen species (RNS). Thus, reacting with superoxide, $\mathrm{NO}^{\bullet}$ produces peroxynitrite $\left(\mathrm{ONOO}^{-}\right)$, a highly reactive oxidant, able to damage many biological molecules and decompose releasing small amounts of $\bullet \mathrm{OH}$ (Radi et al. 2002).

To neutralize the oxidative effects of ROS and RNS, aerobic organisms have evolved a system of biochemical defences (Yu 1994, Davies 2000). An oxidant generation that exceeds the antioxidant capacity of cells results in oxidative stress development (Sies 1997), a deleterious process that has been related to many pathological conditions (Valko et al. 2007, Reed 2011, He \& Zuo 2015) and seems to also be involved in the etiology of IR, primarily in skeletal muscle tissue, and the subsequent development of T2DM (Henriksen et al. 2011). It has also been suggested that oxidant overproduction arises from (i) the mitochondrial electron transport chain in conditions of energy surplus and (ii) the cellular NADPH oxidase activated via angiotensin II (AT1) receptors (Henriksen et al. 2011).

ROS have been traditionally regarded as toxic by-products of metabolism, which, if occurring in a massive extent, may cause organ dysfunction. However, it is now believed that, when moderately produced, they are essential for several physiological processes leading to adaptive cellular responses. This idea is supported by the observation that, at the cellular level, ROS regulate growth, apoptosis and other signaling, whereas at the system level, they contribute to complex functions, including blood pressure regulation, cognitive and immune functions (Brieger et al. 2012). It has also been shown that although accumulation of oxidative damage results in organism death (Muller et al. 2007), several longevity-promoting interventions increase generation of ROS that activate stress responses that are beneficial to the organism and extend life span (Ristow \& Schmeisser 2011). Like ROS, RNS play a dual role as they can be either harmful or beneficial to living systems. Nitric oxide, early identified as a signaling molecule in blood vessel modulation (Ignarro et al. 1987, Bogdan 2001) and now known as a regulator of important physiological processes (Bogdan 2001), can cause cellular toxicity either damaging metabolic enzymes or generating peroxynitrite by reaction with superoxide (Pacher et al. 2007).

Similarly, mitochondrial ROS production is thought to both play a major role in tissue oxidative damage and dysfunction and provide protection against excessive tissue dysfunction (Venditti \& Di Meo 2006), even though it is apparent that in various conditions remarkable contribution to tissue oxidative stress and protection is provided by other sources of ROS and RNS (Di Meo et al. 2016). The issue is complicated by the strong interaction existing among the various cellular sources of ROS (Camões et al. 2009, Vannuvel et al. 2013), which makes it difficult to establish what source of reactive species plays a prominent role in different physiological and pathological conditions. However, it is likely that the relevance of the role played in cellular damage and signal transduction is dependent on the type of reactive species produced and localization of their source and their targets (Finkel \& Holbrook 2000).

Although ROS, such as $\bullet \mathrm{OH}$, may cause irreversible, non-specific damage to target macromolecules, $\mathrm{H}_{2} \mathrm{O}_{2}$ and/or $\mathrm{O}_{2}{ }^{--}$are the best candidates as signaling molecules. Both species are formed by enzymes and their concentrations are enzymatically controlled. However, precise identification of ROS involved in a signaling event is not easy. Usually, one ROS gives rise to other species and their effects on a target molecule may not be very different from each other.

The complexity of the role played by the reactive species in the physiological and pathological conditions http://joe.endocrinology-journals.org DOI: 10.1530/JOE-16-0598
๑) 2017 Society for Endocrinology Printed in Great Britain
Published by Bioscientifica Ltd 
is apparent examining the action of such species in glucose uptake.

\section{Reactive species and insulin signaling}

Oxidants have been consistently implicated in the development of IR and subsequent T2DM. In fact, although the observation that the cellular models of IR are characterized by persistently elevated ROS levels (Houstis et al. 2006) suggests that ROS contribute to IR, there are other data that suggest a completely opposite view. At present, it is well established that $\mathrm{H}_{2} \mathrm{O}_{2}$ is able to exert stimulatory or inhibitory effects on insulin signaling, depending on the concentration of $\mathrm{H}_{2} \mathrm{O}_{2}$ and/or the site of production relative to various components of insulin signaling pathway(s) (Rindler et al. 2013). However, it is unclear as to why in certain cellular and animal models, increased ROS levels are associated with IR and scavenging the oxidants improves metabolic homeostasis, whereas in other models, increased ROS levels are associated with improved insulin sensitivity and antioxidants make things worse. Possible explanations of the discordant results include differences in sources and rates of ROS generation, changes in the function of oxidants depending on the disease stage and differences in the various metabolic models used. Furthermore, because redox homeostasis presumably has a narrow biological window, too high or too low levels of oxidants might produce similar pathological effects.

\section{NOX-derived $\mathrm{H}_{2} \mathrm{O}_{2}$}

The membrane-bound NADPH oxidases constitute the only enzyme family with the sole function to produce ROS. A NADPH oxidase generating $\mathrm{O}_{2}{ }^{\cdot-}$ was first identified in phagocytes, which showed bactericidal activity (Babior 1999). The phagocyte NADPH oxidase is composed of two membrane proteins P22PHOX and GP91PHOX (cytochrome b558 heavy chain, later designated as NOX2, which is the catalytic subunit of the enzyme), three cytosolic proteins P67PHOX, P47PHOX and P4OPHOX and a small GTP-binding protein RAC (Chanock et al. 1994). In resting cells, the enzyme is dormant, and its components are distributed between the cytosol and plasma membrane. Bacterial infection induces translocation of the cytosolic components to the phagosome membrane where they associate with cytochrome b558 and give rise to the catalytically active NADPH oxidase (Chanock et al. 1994).
The presence of NOX2 homologs was firstly suggested by the observation that $\mathrm{O}_{2}^{--}$is produced in a NADPHdependent manner in no phagocytic cells, in which NOX2 is not expressed (Suh et al. 1999). To date, five NOX isoforms (NOX1, NOX2, NOX3, NOX4 and NOX5) and two related enzymes (DUOX1 and DUOX2), which have different regulation and specific subcellular localization and generate distinct ROS, have been reported (Katsuyama 2010). NOX1, NOX2 and NOX3 generate $\mathrm{O}_{2}{ }^{--}$. NOX4, NOX5, DUOX1 and DUOX1 produce $\mathrm{H}_{2} \mathrm{O}_{2}$.

Recent studies have shown that skeletal muscle expresses NOX including the catalytic NOX2, NOX4, DUOX1 and DUOX2 enzymes in various subcellular compartments (Sakellariou et al. 2014). In particular, NOX2 and NOX4 appear to be present on the sarcolemma (Javesghani et al. 2002), whereas NOX4, but not NOX2, is present in skeletal muscle mitochondria (Sakellariou et al. 2013).

Skeletal muscle generates ROS both under resting conditions and during exercise. However, although the contribution of mitochondria to ROS generation is well established (Di Meo \&Venditti 2001), a potential role for NOX remains uncertain. NOX2-derived ROS are proposed to play a role in $\mathrm{Ca}^{2+}$ release from the sarcoplasmic reticulum, a key signaling step in muscle contraction (Hidalgo et al. 2006). Furthermore, both NOX2 and NOX4 are involved in the proliferation of skeletal muscle precursor cells (Mofarrahi et al. 2008).

In the 1970s, substantial evidence was obtained that exogenously added $\mathrm{H}_{2} \mathrm{O}_{2}$ could mimic the insulin signaling activity (Czech et al. 1974a) and oxidation of key fat cell sulfhydryls in response to insulin receptor interaction plays a role in mediating the glucose transport activation (Czech et al. 1974b). A few years later, insulin was shown to activate a plasma membrane enzyme system with the properties of an NADPH oxidase resulting in the downstream production of $\mathrm{H}_{2} \mathrm{O}_{2}$ (May \& de Haen 1979), which plays a role in facilitating normal signal transduction by insulin.

\section{Beneficial effect of ROS}

In skeletal muscle, insulin receptor binding increases the activity of NOX localized on the plasma membrane, by PI3K activation, thus leading to enhanced $\mathrm{H}_{2} \mathrm{O}_{2}$ concentration proximal to the receptor (Espinosa et al. 2009).

NOX-derived $\mathrm{H}_{2} \mathrm{O}_{2}$ is able to enhance as well as reduce insulin sensitivity. Indeed, NOX4-deficient mice display greater IR than wild-type mice when fed a highfat diet (Li et al. 2012). Further support for a NOX role in

Published by Bioscientifica Ltd. 
the enhancement of insulin sensitivity comes from the observation that mice lacking one of the key enzymes involved in ROS elimination, glutathione peroxidase 1 (GPX1), resist to high-fat diet-induced whole body IR (Loh et al. 2009). The dependence of the increased insulin sensitivity in GPX1 (-/-) cells on ROS is demonstrated by the observation that it is decreased by the antioxidant $\mathrm{N}$-acetylcysteine to that of control mice. The NOX involvement is demonstrated by the finding that AKT phosphorylation stimulated by insulin is higher in the GPX1 (-/-) cells and is suppressed by treatment with diphenylenene iodonium chloride, a NOX inhibitor (Loh et al. 2009). Furthermore, insulin-stimulated PTEN oxidation is increased in GPX1 (-/-) cells and is suppressed by NOX inhibition.

It has been reported that the protein tyrosine phosphatases PTP-1B and PTEN, known to negatively regulate insulin signaling pathway (Elchebly et al. 1999, Wijesekara et al. 2005), are transiently oxidized and inactivated by $\mathrm{H}_{2} \mathrm{O}_{2}$ (Tonks 2006). Therefore, the data from GPX1 (-/-) mice support the ability of $\mathrm{H}_{2} \mathrm{O}_{2}$, produced by NOX to stimulate the insulin signaling cascade by inhibiting protein tyrosine phosphatases. Moreover, analysis of individuals with selenoprotein deficiency suggests that these observations may potentially extend to humans as well (Schoenmakers et al. 2010).

\section{Harmful effect of ROS}

Harmful effect of NADPH-produced ROS on insulin sensitivity is found after exposure of cultured cardiomyocytes to high glucose, which leads to NADPH oxidase (NOX2) activation, resulting from RAC1 activation and P47PHOX translocation and ROS production (Balteau et al. 2011). Hyperglycemia also impairs insulin signaling that is rescued by treatment with gp91ds-tat, a specific inhibitor of NOX2 activation suggesting that such an activation and ROS production are responsible for IR.

Although the etiology of skeletal muscle IR is multifactorial, there is clear evidence that one contributor is overactivity of the renin-angiotensin system (RAS).

The RAS is known for its role in the regulation of several physiological processes, including blood pressure, cardiac mass and contractility, and fluid balance (Schmieder et al. 2007). Angiotensinogen (Agt) is cleaved by the enzymes renin and angiotensin-converting enzyme (ACE) successively, to form angiotensin II (Ang II), the main bioactive peptide of this system. RAS overactivity is linked with the multifactorial etiology of hypertension.
Ang II exerts its physiological actions, primarily via two G-protein-coupled receptors, Ang II type 1 receptor (AT1R) and type 2 receptor (AT2R) (Schmieder et al. 2007). Its hypertensive effect is mediated through AT1R so that AT1R blockers and ACE inhibitors are commonly used for antihypertensive therapy (Schmieder et al. 2007).

Several clinical trials have shown that treatment of hypertensive patients with the previously mentioned drugs result in lower risk for T2DM when compared with other antihypertensive agents (Kim et al. 2006). Moreover, AT1R blockade ameliorates IR and glucose intolerance in several rodent models of obesity (Chu et al. 2006). These effects agree with previous observations showing that systemic delivery of Ang II in animal models is associated with defects in vascular delivery of glucose and insulin to skeletal muscle (Richey et al. 1999) and with impairment of the glucose transport system in this tissue (Ogihara et al. 2002).

Studies on cultured L6 myocytes indicated that Ang II inhibited the insulin-PI3K signaling pathway stimulating serine phosphorylation of IRS-1, one of the major substrates of the insulin receptor kinase (Wei et al. 2006). IRS-1 contains multiple tyrosine phosphorylation motifs that serve as docking sites for $\mathrm{SH} 2$ domains that mediate the metabolic and growth-promoting functions of insulin (Folli et al. 1997). However, IRS-1 also contains over 30 potential serine/threonine phosphorylation sites, whose phosphorylation inhibits insulin stimulation of tyrosine phosphorylation, resulting in the inhibition of downstream insulin signaling molecules (Andreozzi et al. 2004). Ang II induces serine phosphorylation at both sites and inhibits downstream signaling, including Akt phosphorylation, GLUT-4 translocation to the sarcolemma and $\mathrm{NO}^{\bullet}$ production in the endothelium (Folli et al. 1997, Andreozzi et al. 2004).

The Ang II effects seem to depend on the capacity of Ang II, acting through the AT1R, to generate ROS in various cell types including skeletal muscle (Shiuchi et al. 2004, Blendea et al. 2005). Indeed, skeletal muscle superoxide production, as assessed by ethidium fluorescence, was shown to be significantly enhanced in rats infused with Ang II for 2 weeks, and the observed increase was greatly attenuated by AT1R blockade with valsartan (Shiuchi et al. 2004). Moreover, increased superoxide content and IR were found in soleus muscle with local elevated Ang II levels (Blendea et al. 2005). Valsartan, angiotensin II receptor blocker, and tempol, a superoxide dismutase mimetic, reduced superoxide production and improved insulin sensitivity (Blendea et al. 2005), http://joe.endocrinology-journals.org DOI: 10.1530/JOE-16-0598
๑) 2017 Society for Endocrinology Printed in Great Britain
Published by Bioscientifica Ltd 
suggesting that Ang II impairs insulin sensitivity at least in part through the generation of ROS. However, it was not known whether Ang II-induced ROS production in skeletal muscle was mainly through NADPH oxidase and consequently contributed to IR in skeletal muscle.

The studies on cultured L6 myocytes also provided the first evidence for the involvement of NADPH in Ang II-induced IR (Wei et al. 2006). Indeed, they demonstrated that Ang II increased NADPH oxidase activity, thereby increasing ROS generation and impairing insulin-induced IRS tyrosine phosphorylation, AKT activation and GLUT4 translocation to plasma membranes. AT1R block by losartan or NADPH oxidase inhibition by apocynin suppressed ROS production and restored insulin-stimulated IRS1, AKT activation and GLUT4 translocation. Furthermore, knockdown of P47phox reduced NADPH oxidase activity and improved insulin-mediated AKT phosphorylation and GLUT4 translocation in the presence of Ang II. However, the study did not clarify the intermediate steps linking ROS to IR in skeletal muscle.

ROS activate multiple transcription factors, including NF-kB (Kamata et al. 2002), whose activation is involved in high-fat diet-induced liver IR in mice (Cai et al. 2005). To determine the role of ROS-mediated NF- $\mathrm{KB}$ activation in blunting insulin effects on skeletal muscle, a study employing transgenic hypertensive (Ren-2) rats and Ang II-treated myotubes was performed (Wei et al. 2008). The results of the study suggested that Ang II-induced ROS generation via NADPH oxidase activates NF-kB, which in turn contributes to skeletal muscle IR.

Obesity seems to play a role in the stimulation of RAS and then in the onset of IR. In fact, obesity is associated with overactivation of both systemic and adipose RAS in humans and animals (Kalupahana \& Moustaid-Moussa 2011). In humans, obesity is associated with increases in plasma angiotensinogen (Engeli et al. 2005), renin (Uckaya et al. 1999), ACE and Ang II (Engeli et al. 2005). The increase in plasma renin levels in obesity is likely secondary to the increased sympathetic tone present in obese individuals (Troisi et al. 1991). Adipose tissue renin, ACE and AT1 expression are also increased in obesity (Gorzelniak et al. 2002). Most, but not all studies show that adipose Agt expression is also higher in obese humans (Goossens et al. 2007). Moreover, weight loss leads to reductions in plasma Agt, renin, ACE and adipose Agt levels (Kalupahana \& Moustaid-Moussa 2011). Animal studies show that, similar to humans, both systemic and adipose RAS components are overexpressed in most dietinduced obese rodent models (Boustany et al. 2004).

\section{Mitochondria-derived $\mathrm{H}_{2} \mathrm{O}_{2}$}

It has now been about 50 years since it was showed that electron transfer along mitochondrial respiratory chain leads to ROS formation (Jensen 1966, Loschen et al. 1974). The primary reactive species generated within mitochondria by univalent auto-oxidation of electron carriers is $\mathrm{O}_{2}{ }^{--}$(Turrens \& Boveris 1980), which is converted by enzymes called superoxide dismutases (SOD) to $\mathrm{H}_{2} \mathrm{O}_{2}$, which can be reduced by $\mathrm{Fe}^{2+}$ ion to - $\mathrm{OH}$ radical (Fenton reaction). Although the main sites involved in mitochondrial ROS production are believed to be localized at Complexes I and III, succinate-dependent ROS production by Complex II from rat skeletal muscle and glycerol 3-phosphate-dependent production by Complex II from several rat tissues have also been reported (Venditti et al. 2013).

To date, the relative importance of each mitochondrial site to ROS production is still controversial, but their localization is important for establishing ROS effects as it determines if $\mathrm{O}_{2}^{--}$is produced in the mitochondrial matrix or in the intermembrane space. Thus, both generators of Complex I and Complex III release $\mathrm{O}_{2}{ }^{*-}$ into the matrix where it can damage mitochondrial DNA, whereas Complex III generator also releases $\mathrm{O}_{2}{ }^{-}-$into the intermembrane space, where it has easier access to the cytosol (Brand 2010).

\section{Mitochondrial ROS production in insulin resistance}

Mitochondria-derived oxidative stress is fairly well established as a mechanism underlying the pathological complications associated with diabetes (Brownlee 2001). However, its role as a primary factor in the development of IR (and subsequent overt diabetes), although long suspected, has been based largely on indirect evidence (Evans et al. 2002, 2005). The first direct evidence indicating a causal role was reported by Houstis and coworkers (Houstis et al. 2006) who utilized two distinct means of inducing IR in 3T3-L1 adipocytes, TNF $\alpha$ and dexamethasone treatment. In both models, IR induction resulted in elevated ROS production prior to any detectable decline in insulin sensitivity, fulfilling the criterion that the establishment of a 'causal' mechanism within any process requires that causal stimulus must precede the effect. Furthermore, using different mitochondrial- and non-mitochondrial-targeted approaches, scavenging either $\mathrm{O}_{2}{ }^{--}$or $\mathrm{H}_{2} \mathrm{O}_{2}$, insulin sensitivity was partially restored in all cases, fulfilling the criterion that removal 
or inhibition of the causal stimulus must attenuate or prevent the effect (Houstis et al. 2006).

Subsequent studies, using various animal models and mitochondrial-targeted approaches, provided strong experimental evidence of a link between mitochondrial-derived ROS and IR in vivo. Several studies were performed modifying the antioxidant potential of muscle mitochondria either by treating animals with mitochondrial-targeted antioxidants or increasing their expression. Although $\mathrm{O}_{2}{ }^{--}$dismutation to $\mathrm{H}_{2} \mathrm{O}_{2}$ can occur spontaneously, the radical is rapidly converted to $\mathrm{H}_{2} \mathrm{O}_{2}$ by mitochondrial SOD. Complex I-derived $\mathrm{O}_{2}{ }^{-}$- is released into the matrix (Muller et al. 2004) and is eliminated in such a compartment by a form of SOD containing manganese in the active site (MnSOD) (Fridovich 1995). Part of the $\mathrm{O}_{2}{ }^{*-}$ released in the intermembrane space by Complex III generator is eliminated by a different SOD isozyme, containing copper and zinc ( $\mathrm{Cu}$ and $\mathrm{ZnSOD}$ ) (Okado-Matsumoto \& Fridovich 2001). In turn, $\mathrm{H}_{2} \mathrm{O}_{2}$ is scavenged by catalase (CAT), peroxiredoxin (PRDX) or GPX. Thus, MnSOD overexpression was found to improve insulindependent skeletal muscle glucose uptake and whole body insulin sensitivity in high-fat-fed rodents (Hoehn et al. 2009, Boden et al. 2012). Furthermore, evidence was provided that mitochondrial superoxide production is a common feature of many different models of IR and, in particular, IR was rapidly reversible upon exposure to agents that act as mitochondrial uncouplers, respiratory chain inhibitors or mitochondrial MnSOD mimetics (Hoehn et al. 2009).

Moreover, overexpression of peroxiredoxin 3 (PRDX3), a PRDX isoform located in mitochondria, produced significantly lower amount of $\mathrm{H}_{2} \mathrm{O}_{2}$ in skeletal muscle, reduced blood glucose levels and protected against IR induced by high-fat diet (Chen et al. 2008). Support for a role of mitochondrial $\mathrm{H}_{2} \mathrm{O}_{2}$ in IR impairment was provided by the observation that attenuating the increase in mitochondrial $\mathrm{H}_{2} \mathrm{O}_{2}$ release due to high-fat diet either by treating rats with the mitochondrial-targeted antioxidant SS31 (a small, cell permeable peptide) or by genetically engineering the overexpression of catalase in mitochondria of mouse muscle, completely preserved insulin sensitivity (Anderson et al. 2009). Similarly, it was showed that mice with targeted overexpression of the human catalase gene to mitochondria (MCAT) were protected from age-induced decrease in muscle mitochondrial function, energy metabolism and lipidinduced muscle IR (Lee et al. 2010).
The above reports provide strong evidence that mitochondrial-derived ROS are a signal for modulating insulin sensitivity. However, they do not clarify which species mediates the development of IR. The observation that MnSOD mimetics (Chen et al. 2008) and MnSOD overexpression (Hoehn et al. 2009, Boden et al. 2012) are able to limit the development of IR and to improve glucose tolerance when administered to high-fat-fed mice suggested a role for $\mathrm{O}_{2}{ }^{-}$in the negative regulation of insulin sensitivity (Hoehn et al. 2009). However, in normal cell, the steady-state concentration of $\mathrm{O}_{2}{ }^{--}$is maintained at very low levels by endogenous SODs, which increase the rate of its dismutation to that of a diffusion-controlled process (Forman \& Fridovich 1973, Liochev \& Fridovich 2007). Furthermore, recent observation that SOD2 overexpression does not alleviate muscle insulin resistance alone and does not exert additive effect when combined with increased $\mathrm{H}_{2} \mathrm{O}_{2}$ scavenging suggest that treatments designed to enhance $\mathrm{H}_{2} \mathrm{O}_{2}$ removal provide greater protection against IR than those that target $\mathrm{O}_{2}{ }^{--}$(Lark et al. 2015). On the other hand, there are other reasons suggesting the primary role of $\mathrm{H}_{2} \mathrm{O}_{2}$ in insulin signaling inhibition. The mechanism by which ROS initiate cellular signaling is thought to involve modifications of thiol groups of cysteine residues of target protein. $\mathrm{O}_{2}{ }^{-}$is able to oxidize thiols to thiyl radical, which can initiate a chain reaction, but the rate constants for this reaction are quite slow, probably no more than $10^{3} \mathrm{M}^{-1} \mathrm{~s}^{-1}$ (Winterbourn \& Metodiewa 1995), which is insignificant in comparison to the rate constant at which $\mathrm{O}_{2}{ }^{--}$is reduced to $\mathrm{H}_{2} \mathrm{O}_{2}$ by MnSOD $\left(>10^{9} \mathrm{M}^{-1} \mathrm{~s}^{-1}\right)$ (Forman \& Fridovich 1973). Conversely, thiol group oxidation by $\mathrm{H}_{2} \mathrm{O}_{2}$ forms reactive sulfenic acid (-SOH) that, in turn, can form disulfide bonds with nearby cysteines (-S-S-) or undergo further oxidation to sulfinic $\left(-\mathrm{SO}_{2} \mathrm{H}\right)$ or sulfonic $\left(-\mathrm{SO}_{3} \mathrm{H}\right)$ acid. These modifications result in changes in protein structure and function, which are in part reversible by reducing systems such as thioredoxin and peroxiredoxins (Roos \& Messens 2011). Furthermore, both thermodynamic and kinetic considerations suggest that among possible oxidation states of cysteine, formation of sulfenic acid derivatives or disulfides can be relevant as thiol redox switches in signaling (Forman et al. 2010).

Thus, in terms of a signaling role, $\mathrm{H}_{2} \mathrm{O}_{2}$ is considered to fulfill the requirements of a second messenger, whereas $\mathrm{O}_{2}{ }^{--}$is more likely to function simply as a precursor of $\mathrm{H}_{2} \mathrm{O}_{2}$ rather than as a primary second messenger (Forman et al. 2010). 


\section{Impairment of insulin signaling}

Although the mechanisms by which mitochondrial $\mathrm{H}_{2} \mathrm{O}_{2}$ production impairs insulin signaling are not fully characterized, the link between ROS production and IR has been ascribed to alterations in various intracellular signaling pathways. Among the several proteins proposed as potential effectors, there are various kinases such as PKCs, IKK $\beta$, JNK and p38 MAP kinase. These kinases have been postulated to catalyze the phosphorylation of serine residues in IRS- 1 inhibiting its activity and directing it for degradation by the proteasome (Paz et al. 1997, Zhande et al. 2002). Such effects culminate with a reduction in the phosphorylation of tyrosine residues of IRS-1 by insulin, blocking its downstream signal transduction (Tirosh et al. 1999, Bloch-Damti \& Bashan 2005, Evans et al. 2005).

In particular, c-Jun NH2-terminal kinase 1 (JNK1) appears to be a major factor in IR development because of its capacity to inhibit IRS activity via phosphorylation of $\mathrm{Ser}^{307}$, a post-translational modification preventing the interaction between insulin receptor and IRS (Aguirre et al. 2000, 2002).

It is worth noting that, contrary to the results of cellbased experiments, subsequent study performed on mice showed that IRS1 ser ${ }^{307}$ is required to maintain normal insulin signaling (Copps et al. 2010).

However, whatever the serine phosphorylated may be, there is evidence that activation of the JNK pathway is important for maintaining IR (Kaneto et al. 2004) and that the increases in body mass and blood glucose levels and the loss of insulin sensitivity induced by high-fat diet are decreased in JNK1-knockout mice relative to wild-type control animals (Hirosumi et al. 2002).

A direct link between mitochondrial $\mathrm{H}_{2} \mathrm{O}_{2}$ production and JNK1 activation has not yet been demonstrated, but an inverse relationship between protein tyrosine phosphatase PTP-1B activity and JNK1 activation has been shown by treating H4IIEC hepatocytes with increasing concentrations of $\mathrm{H}_{2} \mathrm{O}_{2}$ (Iwakami et al. 2011). With relatively low concentrations of $\mathrm{H}_{2} \mathrm{O}_{2}(\leq 5.0 \mu \mathrm{M})$, PTP-1B activity was inhibited and insulin-stimulated phosphorylation IRS and Akt was enhanced. With higher $\mathrm{H}_{2} \mathrm{O}_{2}$ concentrations ( $\left.\geq 5 \mu \mathrm{M}\right)$, JNK1 was activated, whereas insulin-stimulated IRS and Akt phosphorylation was reduced. These data clearly show that insulin sensitivity is modulated by changes in $\mathrm{H}_{2} \mathrm{O}_{2}$ concentration. Moreover, the observation that suppression of $\beta$-oxidation (Koves et al. 2008) or overexpression of mitochondrial antioxidant enzymes that remove $\mathrm{H}_{2} \mathrm{O}_{2}$ (Chen et al. 2008,
Anderson et al. 2009) decreases the loss of insulin sensitivity induced by high-fat diet, suggests that the increase in mitochondrial $\mathrm{H}_{2} \mathrm{O}_{2}$ generation contributes to obesity-linked IR. If so, mitochondrion functions as a refined sensor of substrate availability changes, able to adjust metabolism to optimize use and clearance of available substrates.

Another possibility is that elevated $\mathrm{H}_{2} \mathrm{O}_{2}$ release may directly target a key component of the glucose uptake process itself. An idea requiring further investigation is that elevated mitochondrial $\mathrm{H}_{2} \mathrm{O}_{2}$ release may contribute to high-fat diet-induced IR leading to the dissociation of hexokinase (HK) from mitochondria.

It has been shown that glucose phosphorylation, an integral step for insulin-stimulated glucose uptake, is functionally impaired in high-fat diet-fed rats (Furler et al. 1997, Halseth et al. 2000) and T2DM patients (Bonadonna et al. 1996). Glucose phosphorylation is catalyzed by $\mathrm{HK}$, and gene and protein expression of HKII, the predominant isoform found in skeletal muscle, are increased in response to insulin (Vogt et al. 2000) but depressed in patients with T2DM (Kruszynska et al. 1998, Pendergrass et al. 1998). HKI and HKII can also bind to the mitochondrial outer membrane through interactions with mitochondrial porin in skeletal muscle (AnflousPharayra et al. 2007). Interestingly, overexpression of HKII in insulin-resistant mice fed a high-fat diet does not improve insulin-stimulated glucose uptake (Fueger et al. 2004). One possibility to explain this observation is that glucose phosphorylation is not solely a function of HKII content, but also dependent upon the subcellular localization of $\mathrm{HK}$ on mitochondria. When bound to mitochondria in skeletal muscle, HK displays greater sensitivity for ATP derived from mitochondria than exogenous ATP (Viitanen et al. 1984), suggesting that HK association with mitochondria provides a bioenergetic advantage to glucose phosphorylation. In both rodent (Chen-Zion et al. 1992) and (Vogt et al. 1998) human striated muscle, HKII association with the mitochondrial outer membrane is promoted by insulin via Akt phosphorylation of HKII (Pastorino et al. 2005) and glycogen synthase kinase-3b (GSK-3b) inhibition (Cross et al. 1995), a basally active negative regulator of glycogen synthesis. The inhibition of GSK-3b decreases the phosphorylation tone on VDAC, increasing the binding affinity between VDAC and HK (Pastorino et al. 2005). GSK-3b activity is increased during nutrient overload (Eldar-Finkelman et al. 1999) and oxidative stress (Dokken et al. 2008), and musclespecific overexpression of GSK-3b is casually linked to IR

Published by Bioscientifica Ltd 
(Pearce et al. 2004). In addition, exogenous $\mathrm{H}_{2} \mathrm{O}_{2}$ has been shown to dissociate HKII from mitochondria in cultured cardiomyocytes (Wu et al. 2011a,b), providing a potential direct link between mitochondrial/cellular redox control and $\mathrm{HK}$ association with mitochondria.

\section{Mechanisms of $\mathrm{H}_{2} \mathrm{O}_{2}$ generation}

There are several mechanisms by which obesity may lead to an increase in mitochondrial $\mathrm{O}_{2}{ }^{--}$and $\mathrm{H}_{2} \mathrm{O}_{2}$ production. A first mechanism invokes the inverse relationship between the rates of electron flow and electron leak along the respiratory chain.

The rate of the electron flow and tetravalent reduction of $\mathrm{O}_{2}$ is modified in response to cellular energy need, which is prevalently expressed by cytosolic ADP concentration. When the cellular demand for energy is high, ATP breakdown to ADP and phosphate increases and, with the greater ADP availability, respiration rate also increases causing ATP regeneration. Respirations in different mitochondrial metabolic states were defined as State 4 or basal respiration and State 3 or active respiration (Chance \& Williams 1956). In in vitro experiments, State 4 occurs in the presence of respiratory substrates but not of ADP and is characterized by rate of $\mathrm{O}_{2}$ consumption lower than that observed in State 3, which occurs in the presence of ADP.

The energy released during State 4 is used to restore the proton gradient dissipated because of the presence of mechanisms that uncouple oxidative phosphorylation from ATP synthesis, inducing the leak of protons back in the mitochondrial matrix. During State 3, the fast energy release, linked to the fast dissipation of the proton gradient of the inner mitochondrial membrane, is turned toward the ATP synthesis. The presence of ADP also decreases the reduction degree of the components of the respiratory chain so that in the State 3 each component of the chain is more oxidized than that in the State 4. As a consequence, the rate of electron leak and univalent reduction of $\mathrm{O}_{2}$ is higher during State 4 than during State 3 . This is why ROS production rate by respiratory chain is controlled by mass action and, at the same $\mathrm{O}_{2}$ concentration, it increases when electron flow slows down increasing the concentration of electron carrier in the reduced form $\left(\mathrm{R}^{\bullet}\right)$ :

$$
d\left[\mathrm{O}_{2}^{-\bullet}\right] / d t=k \cdot\left[\mathrm{O}_{2}\right] \cdot\left[\mathrm{R}^{\bullet}\right]
$$

Although it is unlikely that cells in vivo are ever truly engaged in state 4 respiration, near state 4 conditions likely occur during periods of nutrient overload combined with minimal ATP demand (that is, high caloric intake combined with a sedentary lifestyle).

These conditions would be expected to elevate the reducing pressure within the respiratory chain, accelerate mitochondrial $\mathrm{O}_{2}{ }^{\bullet}$-generation and $\mathrm{H}_{2} \mathrm{O}_{2}$ release and trigger an oxidative shift in the redox environment. In support of this notion, high dietary fat intake generates an increase in partially oxidized lipid intermediates indicative of mitochondrial overload (Koves et al. 2008) and decreases the GSH/GSSG ratio in muscle, indicative of a shift in the intracellular redox environment to a more oxidized state (Anderson et al. 2009). This appears to be mediated by a remarkable increase in the mitochondrial $\mathrm{H}_{2} \mathrm{O}_{2}$ release, which in turn can be due to increased $\mathrm{H}_{2} \mathrm{O}_{2}$ production and/or decreased $\mathrm{H}_{2} \mathrm{O}_{2}$ scavenging in response to the lipid overload (Anderson et al. 2009). Treatment of highfat-fed rodents with SS31 (mitochondrial-targeted small antioxidant peptide), as well as the transgenic expression of the human catalase gene within muscle mitochondria (mCAT), completely blocked the development of IR, as well as the associated increase in $\mathrm{H}_{2} \mathrm{O}_{2}$ release capacity and oxidative shift in the redox environment. Transgenic mice fed a standard chow diet also exhibited improved skeletal muscle insulin sensitivity compared with chowfed WT mice (Anderson et al. 2009).

On the whole, these findings suggest that the degree of insulin sensitivity within a skeletal muscle cell may rely on the degree of reduction or oxidation within the intracellular redox environment. In this context, mitochondrial $\mathrm{H}_{2} \mathrm{O}_{2}$ release and the resulting oxidative shift in the cellular redox environment during nutrient overload is viewed as a metabolic feedback sensor to decrease insulin sensitivity (Fisher-Wellman \& Neufer 2012).

Another mechanism invokes the metabolic shift toward an increased fat consumption occurring in skeletal muscle when fat acid circulating levels increase during obesity (Muoio \&Neufer 2012) and high-fat feeding (Randle et al. 1988, Muoio $\&$ Neufer 2012). Regardless of the energy intake or energy requirement, mitochondrial ROS generation is higher during fatty acid oxidation than that during glycolytic metabolite pyruvate oxidation (Anderson et al. 2007, Seifert et al. 2010). Actually, mitochondrial oxidation of both substrates results in the production of acetyl-CoA that reduces $\mathrm{NAD}^{+}$and $\mathrm{FAD}^{+}$ in the Krebs cycle. However, unlike what happens in pyruvate oxidation, the first stage in fatty acid oxidation is the electron transfer from FADH2, formed by acyl-CoA dehydrogenases, to the electron transport flavoprotein. Electrons are then transferred to the ubiquinone pool located downstream of complex I, the point where electrons coming from NADH enter the electron transport chain.

Published by Bioscientifica Ltd 
In this situation, the reverse electron flow from coenzyme Q (Ernster \& Lee 1967) would bring complex I to a more reduced state, thus enhancing the probability that electrons catalyzing univalent reduction of $\mathrm{O}_{2}$ are released (Fisher-Wellman \& Neufer 2012). In fact, it has been shown that skeletal muscle mitochondria and permeabilized fibers exhibit rates of $\mathrm{H}_{2} \mathrm{O}_{2}$ generation significantly higher in the presence of palmitoylcarnitine than that in the presence of pyruvate (Anderson et al. 2007, Seifert et al. 2010).

Increased dependence on $\beta$-oxidation also results in the accumulation of several fatty acid derivatives some of which have been found to interact with the mitochondrial inner membrane and interfere with electron transport thus stimulating mitochondrial ROS generation (Schonfeld \& Wojtczak 2008, Seifert et al. 2010).

The observation that suppression of $\beta$-oxidation (Koves et al. 2008) as well as selective scavenging of mitochondrial $\mathrm{H}_{2} \mathrm{O}_{2}$ (Chen et al. 2008, Anderson et al. 2009) preserves insulin sensitivity of skeletal muscle in models of diet-induced obesity, suggests that high dietary fat increases ROS production by muscle mitochondria.

Ang II-induced impairment of insulin signaling in skeletal muscle cells (Wei et al. 2006, 2008) and in isolated skeletal muscles (Diamond-Stanic \& Henriksen 2010) is thought to be due to NADPH-oxidase-derived ROS. However, in a model of IR associated with excessive RAS activation, impaired State 3 mitochondrial respiration was observed in mouse skeletal muscle (Takada et al. 2013). Moreover, in mouse skeletal muscles, chronic Ang II infusion caused glucose intolerance and mitochondrial abnormalities together with increased mitochondrial ROS generation (Mitsuishi et al. 2009).

There is also evidence that deletion of Sirt3, which is primarily located in mitochondria (Verdin et al. 2010), impairs insulin signaling in cultured myoblasts, leading to a decrease in tyrosine phosphorylation of IRS-1 (Jing et al. 2011). SIRT3 has a strong impact on mitochondrial antioxidant capacity. Indeed, it deacetylates and activates several enzymes critical in maintaining cellular ROS levels such as SOD2, so that the catalytic activity of the enzyme is diminished when Sirt3 is deleted (Qiu et al. 2010). SIRT3 also stimulates the activity of mitochondrial isocitrate dehydrogenase, IDH2, (Someya et al. 2010), which, via energy-dependent transhydrogenation (Vogel et al. 1999) promotes NADH-supported NADP+ reduction to NADPH, which in turn provides the reducing equivalents for conversion of oxidized to reduced glutathione. Based on these results, the possibility that angiotensin II-induced IR is due to mitochondrial ROS generation causally linked to Sirt3 dysregulation has been investigated (Macconi et al. 2015). Thus, it has been found that angiotensin II-promoted IR in skeletal muscle cells is associated with increase in mitochondrial $\mathrm{O}_{2}{ }^{--}$production, which in turn, leads to decreased Sirt3 expression and activity. The idea that Ang II-induced IR through SIRT3 dysfunction has been supported by the observation that acetyl-Lcarnitine, a modulator of mitochondrial metabolism, restores SIRT3 levels, MnSOD activity, rescuing skeletal muscle cells from mitochondrial superoxide-driven IR (Macconi et al. 2015).

The relative role of NADPH oxidase and mitochondria in ROS generation in Ang II-treated skeletal muscle cells remains unknown. However, there is evidence of cross-talk between NADPH oxidase and mitochondria in regulating ROS generation and that NADPH oxidasederived ROS can trigger mitochondrial ROS formation and vice versa (Dikalov 2011). It is, therefore, conceivable that Ang II-induced NADPH oxidase activation can concur to trigger mitochondrial changes in L6 myotubes leading to IR.

\section{Nitric oxide synthase}

Nitric oxide synthases (NOS) are enzymes catalyzing the conversion of L-arginine into L-citrulline and nitric oxide (NO•) (Radi et al. 2002), a free radical relatively unreactive which, however, can be converted into a number of more reactive derivatives. To date, three isoforms of nitric oxide synthase have been identified. Two isoforms, neuronal NOS (nNOS; type I NOS) and endothelial NOS (eNOS; type III NOS), are expressed constitutively and regulated by the interaction of $\mathrm{Ca}^{2+}$ with calmodulin (Nathan \& Xie 1994). The other isoform, inducible-NOS (iNOS; type II NOS), is induced in response to infection, inflammation or trauma and is not regulated by $\mathrm{Ca}^{2+}$ because it forms a complex with calmodulin at very low concentrations of $\mathrm{Ca}^{2+}$ (Nathan \& Xie 1994).

Recently, iNOS has emerged as an important player in IR, suggesting that RNS can be involved in IR development. High-fat-fed mice (Perreault \& Marette 2001) and rats (Carvalho-Filho et al. 2005) all have significantly greater skeletal muscle iNOS expression compared with their respective controls without an associated increase in eNOS or nNOS. Moreover, the increased expression of iNOS was associated with increased RNS generation and impaired insulin sensitivity in skeletal muscle (CarvalhoFilho et al. 2005). It was also found that high-fat-fed 
mice with a specific disruption in the iNOS gene, which canceled the enzyme activity, were protected from the decrements in both skeletal muscle insulin signaling and insulin-mediated glucose transport observed in highfat-fed wild-type mice (Perreault \& Marette 2001). The authors proposed that the production of $\mathrm{NO}^{\bullet}$ by iNOS was responsible for inducing IR in the wild-type animals. Involvement of $\mathrm{NO}^{*}$ is supported by the observation that soleus muscle exposed to $\mathrm{NO} \bullet$ donors had decreased insulin-stimulated glucose uptake and glycogen synthesis, effects that were associated with reduced insulin-stimulated phosphorylation of IR, IRS-1 and AKT (Carvalho-Filho et al. 2005). However, the previously mentioned result does not allow to exclude the possibility that the effects were due to $\mathrm{NO}^{\bullet}$ derivatives. Indeed, $\mathrm{NO}^{\bullet}$ readily reacts with superoxide to form peroxynitrite, which has been reported to modulate cellular functions through the nitration of tyrosine residues, even though the tyrosine nitration actually depends on reactions between $\mathrm{ONOO}^{-}$and $\mathrm{CO}_{2}$ leading to tyrosine residue radical and nitrogen dioxide $\left(\mathrm{NO}_{2}{ }_{2}\right)$, which couple to form the nitrated product (Radi 2013). In fact, subsequent work showed that peroxynitrite treatment fully reproduced the tyrosine nitration and inhibitory effect of iNOS induction on both insulin-stimulated glucose uptake and PI3K activity (Pilon et al. 2010). However, significant elevation in skeletal muscle iNOS protein content was not found in obese individuals despite evidence for IR, showing that skeletal muscle iNOS is not necessarily increased in all states of IR (Kraus et al. 2012).

\section{Mitochondrial dysfunction and oxidant production}

The two theories centered on mitochondrial function propose different mechanisms to explain the onset of obesity-linked IR in skeletal muscle. In the former, a decrease in mitochondrial fatty acid oxidation, caused by mitochondrial dysfunction and/or reduced mitochondrial content is thought to cause an accumulation of increased levels of intracellular fatty acyl-CoA and diacylglycerol. These molecules activate novel protein kinase $\mathrm{C}$, which in turn activates a serine kinase cascade leading to increased serine phosphorylation of IRS-1 and IR (Lowell \& Shulman 2005). In the latter, enhancement in mitochondrial oxidant production in response to excess fuel relative to demand is viewed as an underlying cause of the development of IR in skeletal muscle (Rindler et al. 2013). Indeed, tissue exposure to ROS results in the stimulation of various kinases, including p38MAPK and JNK1 that is associated with decreased insulin signaling and glucose transport.

We are inclined to think that on the basis of available data, it is possible to propose an integrative model placing ROS production by mitochondria and other cellular sources as the primary consequence of the increase in circulating levels of fatty acids. The enhanced oxidant production, in turn, should cause mitochondrial dysfunction and both should lead to IR. This idea is based on a series of observations. Normally, the rate of mitochondrial ROS generation is rather low and results in minimal damage, because mitochondria have a highly efficient antioxidant defence system able to scavenge a large number of the ROS produced (Venditti et al. 2013). However, when in several circumstances, high rates of ROS production occur, a substantial part of oxidants may escape the scavenging systems. In these conditions mitochondrial DNA, proteins and lipids exposed to high levels of ROS undergo structural alteration and damage, which can result in the impairment of important mitochondrial functions. It is likely that mitochondrial oxidative damage and dysfunction are due to ${ }^{\circ} \mathrm{OH}$ radicals produced within mitochondria. These oxyradicals are highly reactive, short-lived species and are expected to cause damage at or near the site of formation. Therefore, they may inactivate components of the respiratory chain, enzymes of the Krebs cycle and other mitochondrial proteins, leading to mitochondrial dysfunction. Moreover, even though it is extremely unlikely that ${ }^{\circ} \mathrm{OH}$ radicals can be released by mitochondria, oxidative damage to components of cytoplasm and other cellular structures can result from mitochondrial leakage of other ROS, such as $\mathrm{H}_{2} \mathrm{O}_{2}$ that is able to readily cross mitochondrial membranes and reach such structures where, in the presence of $\mathrm{Fe}^{2+}$ ligands, it can generate $\bullet \mathrm{OH}$ radical.

It is conceivable that increased oxidative stress in skeletal muscle may also impair mitochondrial function in T2DM. This idea is supported by the observation that mitochondrial function and structure are impaired in skeletal muscle from rodents placed on high-fat diet and with the altered oxidative stress markers (Bonnard et al. 2008).

It is worth noting that the ROS generation in the cell is also able to strengthen ROS mitochondrial production leading to enhanced damage and dysfunction of the organelles through several mechanisms (Fig. 2).

A process by which ROS production becomes selfamplifying is named ROS-induced ROS release (RIRR) (Zorov et al. 2000). RIRR is generated by circuits requiring

Published by Bioscientifica Ltd 


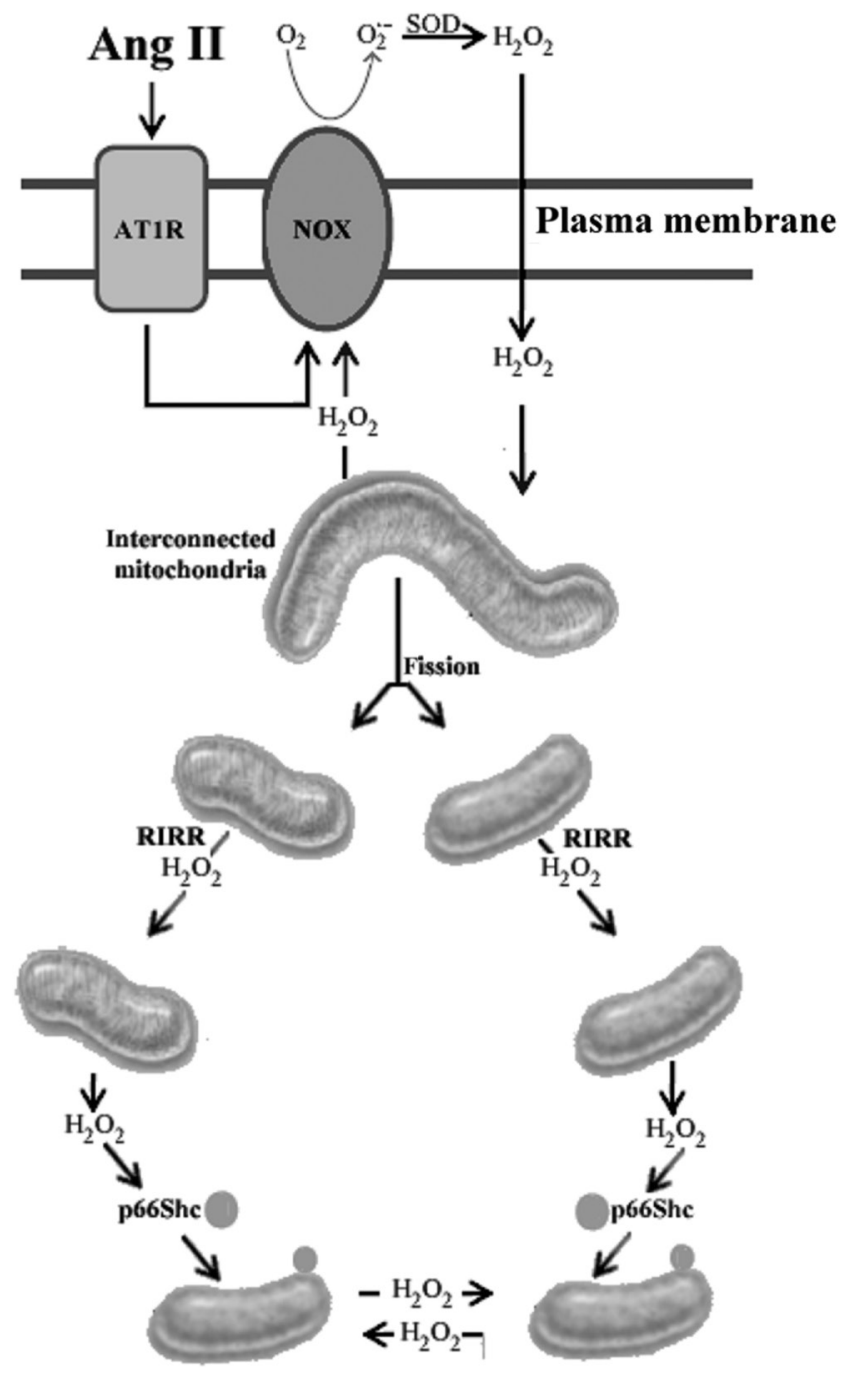

Figure 2

Schematic representation of self-amplifying ROS production in skeletal muscle from obese animals that is supposed to start by Ang II-linked NOX activation. NOX, NADPH oxidase; Ang II, angiotensin II; AT1R, Ang II type 1 receptor; RIRR, ROS-induced ROS release; p66shc, 66-kDa isoform of growth factor adaptor Shc. Adapted, under the terms of the Creative Commons Attribution 4.0 International license, from Di Meo S, Reed TT, Venditti P \& Victor MV (2016) Role of ROS and RNS sources in physiological and pathological conditions. Oxidative Medicine and Cellular Longevity, volume 2016, article ID 1245049.

mitochondrial membrane channels, including the inner membrane anion channel (IMAC) (Garlid \& Beavis 1986) and the mitochondrial permeability transition (MPT) pore (Vercesi et al. 1997), a protein complex that facilitates the traffic of water and small molecules between the mitochondrial matrix and cytoplasm.

A condition that leads to RIRR is the exposure to high oxidative stress resulting in an increase in ROS that reaches a threshold level that triggers the opening of MPT pore. Under oxidative stress, mitochondrial $\mathrm{Ca}^{2+}$ overload takes place, which depresses mitochondrial function (McCormack et al. 1990) and triggers several processes, including MPT pore opening (Zorov et al. 2000). This, in turn, causes collapse of mitochondrial membrane potential and transient increase in ROS generation (Zorov et al. 2000). Such increase can be due to a respiratory chain block caused by MPT induction. In addition to ROS effects on mitochondria where the RIRR is originated, the ROS release into cytosol, which seems to occur through IMAC (Aon et al. 2003), can lead to RIRR activation in the neighboring mitochondria. Thus, ROS trafficking between mitochondria constitutes a positive feedback mechanism for enhanced ROS production potentially leading to significant mitochondrial and cellular injury.

A link between MPT pore opening and mitochondrial dysfunction and IR was demonstrated by inhibiting in vivo and in vitro the protein cyclophilin $\mathrm{D}(\mathrm{CypD})$ that regulates MTP pore opening by directly binding to pore constituent proteins (Taddeo et al. 2014). Indeed, mice lacking CypD were protected from high-fat diet-induced glucose intolerance due to increased glucose uptake in skeletal muscle. Furthermore, in in vitro models of skeletal muscle IR, it was observed that pharmacological inhibition of MTP pore opening with the CypD inhibitor cyclosporine A prevented IR at the level of insulinstimulated GLUT4 translocation to the plasma membrane (Taddeo et al. 2014).

A phenomenon similar to RIRR can also depend on $\mathrm{NO} \bullet$ because $\mathrm{NO} \bullet$ can readily diffuse from mitochondria to cytosol, as well as from cytosol to mitochondria, a process called mitochondria cytosol $\mathrm{NO}^{\bullet}$ cross-talk (Moncada \& Erusalimsky 2002). Within mitochondria, $\mathrm{NO} \cdot$ is able to act as an inducer of permeability transition (Balakirev et al. 1997), through a direct effect on the MPT pore and an indirect effect secondary to oxidative phosphorylation inhibition (Vieira \& Kroemer 2003).

There are reasons to think that ROS, released by mitochondria, can interact not only with other mitochondria but also with other sources of ROS. It is now apparent that there is a substantial interplay between ROS sources, so that activation of one can lead to the activation of the others, resulting in RIRR that further increases ROS production and oxidative stress.

Several examples of the interplay between mitochondrial and NOX-derived ROS have been reported (Daiber 2010). On the whole, they suggest the presence of a feedforward cycle in which NADPH oxidases increase mitochondrial ROS that further activate cytoplasmic NADPH oxidases and increase cellular ROS production.

Published by Bioscientifica Ltd. 
An example is provided by the Ang II-induced increase in $\mathrm{H}_{2} \mathrm{O}_{2}$ production by mitochondria isolated from vascular smooth muscle cells (Doughan et al. 2008). This increase was inhibited by pre-incubation of intact cells with apocynin, a NADPH oxidase inhibitor, and by depletion of P22PHOX subunit of NADPH oxidase. Ang II also induced mitochondrial dysfunction, as documented by increase in state 4 and decrease in state 3 respiration that was attenuated by apocynin suggesting that Ang II induces mitochondrial $\mathrm{H}_{2} \mathrm{O}_{2}$ production and mitochondrial dysfunction by activating the endothelial cell NADPH oxidase.

Mitochondrial ROS production can also lead to and be increased by a process, the mitochondrial fission that is involved in IR. As it is known, mitochondrial shape can be modified through two finely regulated processes of fusion and fission, resulting in elongated, interconnected mitochondrial networks and fragmented, discontinuous mitochondria, respectively (Frazier et al. 2006). In mammals, mitochondrial fission is mediated by the protein dynamin-related protein 1 (DRP1) and the fission protein 1 (FIS1) (Nunnari et al. 2002, Liesa et al. 2009), whereas fusion is mediated by the dynamin-like proteins mitofusins 1 and 2 (MFN1 and MFN2) and the optic atrophy gene 1 (OPA1) (Cipolat et al. 2004, Palmer et al. 2011). The proteins that mediate mitochondrial dynamics are highly regulated and consequently integrated into cellular signaling pathways.

The study of specific changes in mitochondrial shape showed that the loss of fusion or fission activity results in dysfunctional mitochondria suggesting that morphology and function of mitochondria are closely linked (Nunnari \& Suomalainen 2012). The importance of mitochondrial fusion can be explained by the need for exchange of intermembrane space and matrix contents between mitochondria, so that defects and transient stresses may be partially buffered. Conversely, mitochondrial fission should create organelles of the appropriate size for transport along actin or microtubule networks (Nunnari \& Suomalainen 2012).

The fission process and ROS metabolism are strongly linked. On the one hand, ROS are able to influence fusion and fission rates via differential modulation of mitochondrial fission-fusion proteins (Wu et al. 2011a,b) altering the mitochondrial morphology as demonstrated by the observation that acute exposure to $\mathrm{H}_{2} \mathrm{O}_{2}$ of mouse myocytes induces slow fragmentation of the mitochondrial reticulum (Fan et al. 2010). On the other hand, mitochondrial fragmentation leads to reduced respiratory capacity and enhanced ROS production
(Yu et al. 2008). The changes in mitochondrial network structure seem to provide an example of RIRR because ROS play a role in mitochondrial fission and increase ROS generation from restructured mitochondria (Handy \& Loscalzo 2012).

Nitric oxide appears to play opposite roles in mitochondrial fission-fusion. Indeed, it increases mitochondrial fragmentation and cell death in neurodegenerative diseases by its effects on dynaminrelated protein-1 (DRP1), which promotes mitochondrial fission (Cho et al. 2009). Conversely, in myogenesis, $\mathrm{NO}^{\bullet}$ promotes the fusion of mitochondria into an elongated network by inhibiting Drp1-mediated fission (De Palma et al. 2010).

Clear evidence is also available indicating a link between oxidant-induced mitochondrial fission process and IR and impairment of glucose metabolism. In fact, excess palmitate (PA) was found to induce mitochondrial fragmentation and increase fission-related proteins DRP1 and FIS1 in differentiated C2C12 muscle cells. The fragmentation was associated with increased oxidative stress, depolarization, loss of ATP production and reduced insulin-stimulated glucose uptake. Moreover, genetic and pharmacological inhibition of DRP1 attenuated PA-induced mitochondrial fragmentation and IR in C2C12 cells (Jheng et al. 2012). Smaller and shorter mitochondria and increased mitochondrial fission machinery were also found in skeletal muscle of mice with genetic and dietinduced obesity, and inhibition of mitochondrial fission improved the muscle insulin signaling and systemic insulin sensitivity of obese mice. ROS involvement in PA-induced mitochondrial fragmentation was demonstrated by the observation that PA significantly increased intracellular ROS level, whereas the co-treatment with $\alpha$-tocopherol, a ROS scavenger, attenuated ROS generation and PA-induced mitochondrial fragmentation. These findings, showing a relationship between ROS-linked mitochondrial fission and mitochondrial dysfunction and IR in skeletal muscle, suggest that the disruption by ROS of mitochondrial dynamics may underlie the pathogenesis of muscle IR in obesity and T2DM (Jheng et al. 2012).

The notion of alterations in mitochondrial dynamics in insulin-resistant states is supported by other reports. Thus, mitochondrial size is reduced in skeletal muscle of obese and diabetic patients compared to that in lean subjects (Kelley et al. 2002). This alteration in mitochondrial morphology is associated with a repression of the mitochondrial fusion protein MFN2 as demonstrated by the finding that skeletal muscles of both obese and non-obese diabetic patients show a reduced expression

Published by Bioscientifica Ltd 
of MFN2 level compared to control subjects (Bach et al. 2005). It has also been found that MFN2 deficiency in mouse soleus muscles increases $\mathrm{H}_{2} \mathrm{O}_{2}$ concentration, produces mitochondrial dysfunction, activates JNK and blocks insulin-stimulated AKT phosphorylation leading to muscle IR (Sebastián et al. 2012). A major conclusion of the study is that the increase in $\mathrm{H}_{2} \mathrm{O}_{2}$ production is able to induce a decrease in MFN2 level that contributes to impair insulin signaling and insulin sensitivity in skeletal muscle.

Excess oxidants can also augment mitochondrial ROS production by upregulating the expression of the lifespan regulator, the $66-\mathrm{kDa}$ isoform of growth factor adaptor Shc (P66SHC) protein, which has been implicated in the development of aging and agingrelated diseases (Migliaccio et al. 1999). Indeed, mice lacking the P66SHC have reduced $\mathrm{H}_{2} \mathrm{O}_{2}$ generation, are long lived and resistant to a number of age-related pathologies mostly associated with tissue oxidative damage (Migliaccio et al. 1999). The protein seems to reside mainly in the cytosol (Giorgio et al. 2005), with only a marginal fraction localized in the mitochondrial intermembrane space (Nemoto et al. 2006). Thioredoxin (TRX) 1 and glutathione keep the protein in the inactive reduced state. However, stress factors, including ROS, can increase the expression of the protein that is activated by thiol oxidation, which causes a dimer-tetramer transition (Gertz et al. 2008). Activated P66SHC translocates to the mitochondrial intermembrane space where it associates with cytochrome c producing $\mathrm{H}_{2} \mathrm{O}_{2}$, which can trigger MPT pore opening (Giorgio et al. 2005). At present, it is known that $\mathrm{P} 66 \mathrm{SHC}$ is able to increase intracellular ROS levels by exploiting other mechanisms, including the activation of membrane-bound NADPH oxidases (Tomilov et al. 2010) and, possibly, by downregulation of antioxidant enzyme synthesis (Wu et al. 2006).

It is now known that P66SHC-generated $\mathrm{H}_{2} \mathrm{O}_{2}$ is also involved in the regulation of receptor-activated signal transduction pathways. Indeed, insulin activates the redox enzyme activity of p66Shc specifically in adipocytes and that P66SHC-generated ROS regulate insulin signaling through multiple mechanisms, including AKT phosphorylation, FOXO localization and regulation of selected insulin target genes (Berniakovich et al. 2008). It has also been reported that inactivation of $\mathrm{P} 66 \mathrm{SHC}$ in mice improves glucose tolerance and insulin sensitivity (Tomilov et al. 2010) and confers resistance to hyperglycemia-induced endothelial dysfunction (Camici et al. 2008). Furthermore, studies on HeLa cells and murine embryonic fibroblasts (MEFs) have shown that depletion of P66SHC enhanced glucose uptake, and redirects glucose carbon toward anabolic metabolism. This change in metabolism was mediated by the mammalian target of rapamycin (mTOR) because inhibition of mTOR with rapamycin reversed the glycolytic phenotype caused by P66SHC deficiency (Soliman et al. 2014).

Unfortunately, there is little information about a possible involvement of the protein on skeletal muscle IR.

However, examining the role of P66SHC in glucose transport regulation in L6 myoblasts with either reduced or increased levels of the p66 ${ }^{\text {Shc }}$ protein, it was shown that low levels P66SHC increased glucose uptake, whereas high levels reduced it. Furthermore, P66SHC was found to regulate glucose transport by controlling, via MAPK, the integrity of the actin cytoskeleton and by modulating cellular levels of GLUT1 and GLUT3 transporter proteins, which are mainly expressed in L6 myoblasts.

In conclusion, theoretical and experimental evidence appears to indicate that mitochondrial dysfunction is not an early event in the IR development, but rather a complication of the hyperlipidemia-induced ROS production in skeletal muscle, which might promote mitochondrial alterations, lipid accumulation and inhibition of insulin action. On the other hand, the pathways leading to IR may act synergistically because mitochondrial dysfunction can further increase ROS production leading to the establishment of a harmful positive feedback loop.

\section{Declaration of interest}

The authors declare that there is no conflict of interest that could be perceived as prejudicing the impartiality of this review.

\section{Funding}

This work was supported by grants from Italian Ministry of University and Scientific and Technological Research.

\section{Author contribution statement}

All the authors contributed equally to the preparation of the manuscript.

\section{References}

Abdul-Ghani MA, Muller FL, Liu Y, Chavez AO, Balas B, Zuo P, Chang Z, Tripathy D, Jani R, Molina-Carrion M, Monroy A, et al. 2008 Deleterious action of FA metabolites on ATP synthesis: possible link between lipotoxicity, mitochondrial dysfunction, and insulin resistance. American Journal of Physiology 295 E678-E685. (doi:10.1152/ajpendo.90287.2008)

Published by Bioscientifica Ltd. 
Aguirre V, Uchida T, Yenush L, Davis R \& White MF 2000 The c-Jun $\mathrm{NH}_{2}$ terminal kinase promotes insulin resistance during association with insulin receptor substrate- 1 and phosphorylation of Ser ${ }^{307}$. Journal of Biological Chemistry 275 9047-9054. (doi:10.1074/jbc.275.12.9047)

Aguirre V, Werner ED, Giraud J, Lee YH, Shoelson SE \& White MF 2002 Phosphorylation of Ser307 in insulin receptor substrate-1 blocks interactions with the insulin receptor and inhibits insulin action. Journal of Biological Chemistry 277 1531-1537. (doi:10.1074/jbc. M101521200)

Amati F, Dubé JJ, Coen PM, Stefanovic-Racic M, Toledo FGS \& Goodpaster BH 2009 Physical inactivity and obesity underlie the insulin resistance of aging. Diabetes Care 32 1547-1549. (doi:10.2337/ dc09-0267)

Anderson EJ, Yamazaki H \& Neufer PD 2007 Induction of endogenous uncoupling protein 3 suppresses mitochondrial oxidant emission during fatty acid-supported respiration. Journal of Biological Chemistry 282 31257-31266. (doi:10.1074/jbc.M706129200)

Anderson EJ, Lustig ME, Boyle KE, Woodlief TL, Kane DA, Lin CT, Price JW 3rd, Kang L, Rabinovitch PS, Szeto HH, et al. 2009 Mitochondrial $\mathrm{H}_{2} \mathrm{O}_{2}$ emission and cellular redox state link excess fat intake to insulin resistance in both rodents and humans. Journal of Clinical Investigation 119 573-581. (doi:10.1172/JCI37048)

Andreozzi F, Laratta E, Sciacqua A, Perticone F \& Sesti G 2004 Angiotensin II impairs the insulin signaling pathway promoting production of nitric oxide by inducing phosphorylation of insulin receptor substrate-1 on Ser(312) and Ser(616) in human umbilical vein endothelial cells. Circulation Research 94 1211-1218. (doi:10.1161/01.RES.0000126501.34994.96)

Anflous-Pharayra K, Cai ZJ \& Craigen WJ 2007 VDAC1 serves as a mitochondrial binding site for hexokinase in oxidative muscles. Biochimica et Biophysica Acta 1767 136-142. (doi:10.1016/j. bbabio.2006.11.013)

Aon MA, Cortassa S, Marbán E \& O’Rourke B 2003 Synchronized whole cell oscillations in mitochondrial metabolism triggered by a local release of reactive oxygen species in cardiac myocytes. Journal of Biological Chemistry 278 44735-44744. (doi:10.1074/jbc.M302673200)

Ara I, Larsen S, Stallknecht B, Guerra B, Morales-Alamo D, Andersen JL, Ponce-González JG, Guadalupe-Grau A, Galbo H, Calbet JA, et al. 2011 Normal mitochondrial function and increased fat oxidation capacity in leg and arm muscles in obese humans. International Journal of Obesity 35 99-108. (doi:10.1038/ijo.2010.123)

Atgié C, Marette A, Desautels M, Tulp O \& Bukowiecki LJ 1993 Specific decrease of mitochondrial thermogenic capacity in brown adipose tissue of obese SHR/N-cp rats. American Journal of Physiology 265 C1674-C1680.

Babior BM 1999 NADPH oxidase: an update. Blood 93 1464-1476.

Bach D, Naon D, Pich S, Soriano FX, Vega N, Rieusset J, Laville M, Guillet C, Boirie Y, Wallberg-Henriksson H, et al. 2005 Expression of Mfn2, the Charcot-Marie-Tooth neuropathy type 2A gene, in human skeletal muscle: effects of type 2 diabetes, obesity, weight loss, and the regulatory role of tumor necrosis factor $\alpha$ and interleukin- 6 . Diabetes 54 2685-2693. (doi:10.2337/diabetes.54.9.2685)

Bachmann OP, Dahl DB, Brechtel K, Machann J, Haap M, Maier T, Loviscach M, Stumvoll M, Claussen CD, Schick F, et al. 2001 Effects of intravenous and dietary lipid challenge on intramyocellular lipid content and the relation with insulin sensitivity in humans. Diabetes 50 2579-2584. (doi:10.2337/diabetes.50.11.2579)

Balakirev MY, Khramtsov VV \& Zimmer G 1997 Modulation of the mitochondrial permeability transition by nitric oxide. European Journal of Biochemistry 246 710-718. (doi:10.1111/j.14321033.1997.00710.x)

Balteau M, Tajeddine N, de Meester C, Ginion A, Des Rosiers C, Brady NR, Sommereyns C, Horman S, Vanoverschelde JL, Gailly P, et al. 2011 NADPH oxidase activation by hyperglycaemia in cardiomyocytes is independent of glucose metabolism but requires SGLT1. Cardiovascular Research 2 237-246. (doi:10.1093/cvr/cvr230)
Bandyopadhyay G, Standaert ML, Galloway L, Moscat J, \& Farese RV 1997 Evidence for involvement of protein kinase C (PKC)- $\zeta$ and noninvolvement of diacylglycerol-sensitive PKCs in insulinstimulated glucose transport in L6 myotubes. Endocrinology 138 4721-4731. (doi:10.1210/endo.138.11.5473)

Bandyopadhyay G, Standaert ML, Sajan MP, Karnitz LM, Cong L, Quon MJ \& Farese RV 1999 Dependence of insulin-stimulated glucose transporter 4 translocation on 3-phosphoinositide-dependent protein kinase-1 and its target threonine-410 in the activation loop of protein kinase C- $\zeta$. Molecular Endocrinology 13 1766-1772. (doi:10.1210/mend.13.10.0364)

Barazzoni R, Zanetti M, Gortan Cappellari G, Semolic A, Boschelle M, Codarin E, Pirulli A, Cattin L \& Guarnieri G 2012 Fatty acids acutely enhance insulin-induced oxidative stress and cause insulin resistance by increasing mitochondrial reactive oxygen species (ROS) generation

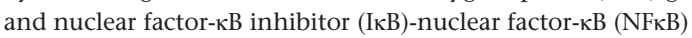
activation in rat muscle, in the absence of mitochondrial dysfunction. Diabetologia 55 773-782. (doi:10.1007/s00125-011-2396-x)

Befroy DE, Petersen KF, Dufour S, Mason GF, de Graaf RA, Rothman DL \& Shulman GI 2007 Impaired mitochondrial substrate oxidation in muscle of insulin-resistant offspring of type 2 diabetic patients. Diabetes 56 1376-1381. (doi:10.2337/db06-0783)

Belfort R, Mandarino L, Kashyap S, Wirfel K, Pratipanawatr T, Berria R, Defronzo RA \& Cusi K 2005 Dose-response effect of elevated plasma free fatty acid on insulin signaling. Diabetes 54 1640-1648. (doi:10.2337/diabetes.54.6.1640)

Berg AH, Combs TP, Du X, Brownlee M \& Scherer PE 2001 The adipocytesecreted protein Acrp30 enhances hepatic insulin action. Nature Medicine 7 947-953. (doi:10.1038/90992)

Berniakovich I, Trinei M, Stendardo M, Migliaccio E, Minucci S, Bernardi P, Pelicci PG \& Giorgio M 2008 p66Shc-generated oxidative signal promotes fat accumulation. Journal of Biological Chemistry $\mathbf{2 8 3}$ 34283-34293.

Bjornholm M, Kawano Y, Lehtihet M \& Zierath JR 1997 Insulin receptor substrate-1 phosphorylation and phosphatidylinositol 3-kinase activity in skeletal muscle from NIDDM subjects after in vivo insulin stimulation. Diabetes 46 524-527. (doi:10.2337/diab.46.3.524)

Blendea MC, Jacobs D, Stump CS, McFarlane SI, Ogrin C, Bahtyiar G, Stas S, Kumar P, Sha Q, Ferrario CM, et al. 2005 Abrogation of oxidative stress improves insulin sensitivity in the Ren-2 rat model of tissue angiotensin II overexpression. American Journal of Physiology 288 E353-E359.

Bloch-Damti A \& Bashan N 2005 Proposed mechanisms for the induction of insulin resistance by oxidative stress. Antioxidant and Redox Signaling 7 1553-1567. (doi:10.1089/ars.2005.7.1553)

Boden G \& Chen XH 1995 Effects of fat on glucose-uptake and utilization in patients with non-insulin-dependent diabetes. Journal of Clinical Investigation 96 1261-1268. (doi:10.1172/JCI118160)

Boden G, Jadali F, White J, Liang Y, Mozzoli M, Chen X, Coleman E \& Smith C 1991 Effects of fat on insulin-stimulated carbohydratemetabolism in normal men. Journal of Clinical Investigation $\mathbf{8 8}$ 960-966. (doi:10.1172/JCI115399)

Boden MJ, Brandon AE, Tid-Ang JD, Preston E, Wilks D, Stuart E, Cleasby ME, Turner N, Cooney GJ \& Kraegen EW 2012 Overexpression of manganese superoxide dismutase ameliorates high-fat diet-induced insulin resistance in rat skeletal muscle. American Journal of Physiology 303 E798-E805. (doi:10.1152/ajpendo.00577.2011)

Bogdan C 2001 Nitric oxide and the regulation of gene expression. Trends in Cell Biology 11 66-75. (doi:10.1016/S0962-8924(00)01900-0)

Bonadonna RC, Del Prato S, Bonora E, Saccomani MP, Gulli G, Natali A, Frascerra S, Pecori N, Ferrannini E, Bier D, et al. 1996 Roles of glucose transport and glucose phosphorylation in muscle insulin resistance of NIDDM. Diabetes 45 915-925. (doi:10.2337/diab.45.7.915)

Bonnard C, Durand A, Peyrol S, Chanseaume E, Chauvin MA, Morio B, Vidal H \& Rieusset J 2008 Mitochondrial dysfunction results from oxidative stress in the skeletal muscle of diet-induced insulin-resistant mice Journal of Clinical Investigation 118 789-800. (doi:10.1172/JCI32601) http://joe.endocrinology-journals.org

DOI: $10.1530 / \mathrm{JOE}-16-0598$ (c) 2017 Society for Endocrinology Printed in Great Britain 
Boudina S, Sena S, Sloan C, Tebbi A, Han YH, O’Neill BT, Cooksey RC, Jones D, Holland WL, McClain DA, et al. 2012 Early mitochondrial adaptations in skeletal muscle to diet-induced obesity are strain dependent and determine oxidative stress and energy expenditure but not insulin sensitivity. Endocrinology 153 2677-2688. (doi:10.1210/ en.2011-2147)

Boushel R, Gnaiger E, Schjerling P, Skovbro M, Kraunsøe R \& Dela F 2007 Patients with type 2 diabetes have normal mitochondrial function in skeletal muscle. Diabetologia 50 790-796. (doi:10.1007/s00125-0070594-3)

Boustany CM, Bhardwaj K, Daugherty A, Brown DR, Randall DC \& Cassis LA 2004 Activation of the systemic and adipose reninangiotensin system in rats with diet-induced obesity and hypertension. American Journal of Physiology 287 R943-R949. (doi:10.1152/ajpregu.00265.2004)

Boveris A, Poderoso JJ, Carreras MC \& Cadenas E 2000 Regulation of mitochondrial respiration by oxygen and nitric oxide. Annals of the New York Academy of Sciences 899 121-135. (doi:10.1111/j.1749-6632.2000.tb06181.x)

Brand MD 2010 The sites and topology of mitochondrial superoxide production. Experimental Gerontology 45 466-472. (doi:10.1016/j. exger.2010.01.003)

Brechtel K, Dahl DB, Machann J, Bachmann OP, Wenzel I, Maier T, Claussen CD, Häring HU, Jacob S \& Schick F 2001 Fast elevation of the intramyocellular lipid content in the presence of circulating free fatty acids and hyperinsulinemia: a dynamic H-1-MRS study. Magnetic Resonance in Medicine 45 179-183. (doi:10.1002/15222594(200102)45:2<179::AID-MRM1023>3.0.CO;2-D)

Brieger K, Schiavone S, Miller FJ \& Krause K-H 2012 Reactive oxygen species: from health to disease. Swiss Medical Weekly 142 w13659.

Brownlee M 2001 Biochemistry and molecular cell biology of diabetic complications. Nature 414 813-820. (doi:10.1038/414813a)

Cai D, Yuan M, Frantz DF, Melendez PA, Hansen L, Lee J \& Shoelson SE 2005 Local and systemic insulin resistance resulting from hepatic activation of IKK- $\beta$ and NF-кB. Nature Medicine 11 183-190. (doi:10.1038/nm1166)

Camici GG, Cosentino F, Tanner FC \& Lüscher TF 2008 The role of p66Shc deletion in age-associated arterial dysfunction and disease states. Journal of Applied Physiology 105 1628-1631. (doi:10.1152/ japplphysiol.90579.2008)

Camões F, Bonekamp NA, Delille HK \& Schrader M 2009 Organelle dynamics and dysfunction: a closer link between peroxisomes and mitochondria. Journal Inherited Metabolic Disease 32 163-180. (doi:10.1007/s10545-008-1018-3)

Caro JF, Dohm LG, Pories WJ \& Sinha MK 1989 Cellular alterations in liver, skeletal muscle, and adipose tissue responsible for insulin resistance in obesity and type II diabetes. Diabetes/Metabolism Reviews 5 665-689. (doi:10.1002/dmr.5610050804)

Carvalho-Filho MA, Ueno M, Hirabara SM, Seabra AB, Carvalheira JB, de Oliveira MG, Velloso LA, Curi R \& Saad MJ 2005 S-nitrosation of the insulin receptor, insulin receptor substrate 1 , and protein kinase B/Akt: a novel mechanism of insulin resistance. Diabetes 54 959-967. (doi:10.2337/diabetes.54.4.959)

Chance B \& Williams GR 1956 The respiratory chain and oxidative phosphorylation. Advances in Enzymology and Related Subjects of Biochemistry 17 65-134. (doi:10.1002/9780470122624.ch2)

Chanock SJ, el Benna J, Smith RM \& Babior BM 1994 The respiratory burst oxidase. Journal of Biological Chemistry 269 24519-24522.

Chanseaume E, Malpuech-Brugère C, Patrac V, Bielicki G, Rousset P, Couturier K, Salles J, Renou JP, Boirie Y \& Morio B 2006 Diets high in sugar, fat, and energy induce muscle type-specific adaptations in mitochondrial functions in rats. Journal of Nutrition 136 2194-2200.

Chanseaume E, Tardy AL, Salles J, Giraudet C, Rousset P, Tissandier A, Boirie Y \& Morio B 2007 Chronological approach of diet-induced alterations in muscle mitochondrial functions in rats. Obesity $\mathbf{1 5}$ 50-59. (doi:10.1038/oby.2007.511)
Cheatham B, Vlahos CJ, Cheatham L, Wang L, Blenis J \& Kahn CR 1994 Phosphatidylinositol 3-kinase activation is required for insulin stimulation of Pp70 S6 kinase, DNA-synthesis, and glucosetransporter translocation. Molecular and Cellular Biology 14 4902-4911. (doi:10.1128/MCB.14.7.4902)

Chen L, Na R, Gu M, Salmon AB, Liu Y, Liang H, Qi W, Van Remmen H, Richardson A \& Ran Q 2008 Reduction of mitochondrial $\mathrm{H}_{2} \mathrm{O}_{2}$ by overexpressing peroxiredoxin 3 improves glucose tolerance in mice. Aging Cell 7 866-878. (doi:10.1111/j.1474-9726.2008.00432.x)

Chen-Zion M, Bassukevitz Y \& Beitner R 1992 Sequence of insulin effects on cytoskeletal and cytosolic phosphofructokinase, mitochondrial hexokinase, glucose 1,6-bisphosphate and fructose 2,6-bisphosphate levels, and the antagonistic action of calmodulin inhibitors, in diaphragm muscle. International Journal of Biochemistry 24 1661-1667. (doi:10.1016/0020-711X(92)90185-4)

Cho D-H, Nakamura T, Fang J, Cieplak P, Godzik A, Gu Z \& Lipton SA 2009 S-Nitrosylation of Drp1 mediates $\beta$-amyloid-related mitochondrial fission and neuronal injury. Science 324 102-105. (doi:10.1126/science.1171091)

Chow L, From A \& Seaquist E 2010 Skeletal muscle insulin resistance: the interplay of local lipid excess and mitochondrial dysfunction. Metabolism 59 70-85. (doi:10.1016/j.metabol.2009.07.009)

Chu KY, Lau T, Carlsson PO \& Leung PS 2006 Angiotensin II type 1 receptor blockade improves $\beta$-cell function and glucose tolerance in a mouse model of type 2 diabetes. Diabetes 55 367-374. (doi:10.2337/ diabetes.55.02.06.db05-1022)

Cipolat S, de Brito MO, Dal Zilio B \& Scorrano L 2004 OPA1 require smitofusin 1 to promote mitochondrial fusion. PNAS 101 15927-15932. (doi:10.1073/pnas.0407043101)

Coen PM \& Goodpaster BH 2012 Role of intramyocelluar lipids in human health. Trends in Endocrinology and Metabolism 23 391-398. (doi:10.1016/j.tem.2012.05.009)

Copps KD, Hancer NJ, Opare-Ado L, Qiu W, Walsh C \& White MF 2010 Irs1 serine 307 promotes insulin sensitivity in mice. Cell Metabolism 11 84-92. (doi:10.1016/j.cmet.2009.11.003)

Crescenzo R, Bianco F, Coppola P, Mazzoli A, Cigliano L, Liverini G \& Iossa S 2013 Increased skeletal muscle mitochondrial efficiency in rats with fructose-induced alteration in glucose tolerance. British Journal of Nutrition 110 1996-2003. (doi:10.1017/S0007114513001566)

Crescenzo R, Bianco F, Coppola P, Mazzoli A, Liverini G \& Iossa S 2014 Subsarcolemmal and intermyofibrillar mitochondrial responses to short-term high-fat feeding in rat skeletal muscle. Nutrition 30 75-81. (doi:10.1016/j.nut.2013.05.022)

Crescenzo R, Bianco F, Coppola P, Mazzoli A, Cigliano L, Liverini G \& Iossa S 2015 The effect of high-fat-high-fructose diet on skeletal muscle mitochondrial energetics in adult rats. European Journal of Nutrition 54 183-192. (doi:10.1007/s00394-014-0699-7)

Cross DA, Alessi DR, Cohen P, Andjelkovich M \& Hemmings BA 1995 Inhibition of glycogen synthase kinase-3 by insulin mediated by protein kinase B. Nature 378 785-789. (doi:10.1038/378785a0)

Cusi K, Maezono K, Osman A, Pendergrass M, Patti ME, Pratipanawatr T, DeFronzo RA, Kahn CR \& Mandarino LJ 2000 Insulin resistance differentially affects the PI3-kinase- and MAP kinase-mediated signaling in human muscle. Journal of Clinical Investigation $\mathbf{1 0 5}$ 311-320. (doi:10.1172/JCI7535)

Czech MP, Lawrence JC Jr \& Lynn WS 1974a Evidence for electron transfer reactions involved in $\mathrm{Cu}^{2+}$-dependent thiol activation of fat cell glucose utilization. Journal of Biological Chemistry 249 1001-1006.

Czech MP, Lawrence JC Jr \& Lynn WS 1974b Evidence for the involvement of sulfhydryl oxidation in the regulation of fat cell hexose transport by insulin. PNAS 71 4173-4177. (doi:10.1073/ pnas.71.10.4173)

Daiber A 2010 Redox signaling (cross-talk) fromand to mitochondria involves mitochondrial pores and reactive oxygen species. Biochimica et Biophysica Acta 1797 897-906. (doi:10.1016/j.bbabio.2010.01.032) http://joe.endocrinology-journals.org

DOI: 10.1530/JOE-16-0598
() 2017 Society for Endocrinology Printed in Great Britain 
Davies KJA 2000 Oxidative stress, antioxidant defenses, and damage removal, repair, and replacement systems. IUBMB Life 50 279-289. (doi:10.1080/15216540051081010)

de Ferranti S \& Mozaffarian D 2008 The perfect storm: obesity, adipocyte dysfunction, and metabolic consequences. Clinical Chemistry $\mathbf{5 4}$ 945-955. (doi:10.1373/clinchem.2007.100156)

De Feyter HM, Lenaers E, Houten SM, Schrauwen P, Hesselink MK, Wanders RJ, Nicolay K \& Prompers JJ $2008 a$ Increased intramyocellular lipid content but normal skeletal muscle mitochondrial oxidative capacity throughout the pathogenesis of type 2 diabetes. FASEB Journal 22 3947-3955. (doi:10.1096/fj.08112318)

De Feyter HM, van den Broek NM, Praet SF, Nicolay K, van Loon LJ \& Prompers JJ $2008 b$ Early or advanced stage type 2 diabetes is not accompanied by in vivo skeletal muscle mitochondrial dysfunction European Journal of Endocrinology 158 643-653. (doi:10.1530/eje-070756)

De Palma C, Falcone S, Pisoni S, Cipolat S, Panzeri C, Pambianco S, Pisconti A, Allevi R, Bassi MT, Cossu G, et al. 2010 Nitric oxide inhibition of Drp1-mediated mitochondrial fission is critical for myogenic differentiation. Cell Death and Differentiation 17 1684-1696. (doi:10.1038/cdd.2010.48)

de Wilde J, Mohren R, van den Berg S, Boekschoten M, Dijk KW, de Groot P, Müller M, Mariman E \& Smit E 2008 Short-term high fat-feeding results in morphological and metabolic adaptations in the skeletal muscle of C57BL/6J mice. Physiological Genomics 32 360-369. (doi:10.1152/physiolgenomics.00219.2007)

DeFronzo RA \& Ferrannini E 1991 Insulin resistance. A multifaceted syndrome responsible for NIDDM, obesity, hypertension, dyslipidemia, and atherosclerotic cardiovascular disease. Diabetes Care 14 173-194. (doi:10.2337/diacare.14.3.173)

Di Meo S \& Venditti P 2001 Mitochondria in exercise-induced oxidative stress. Biological Signals and Receptors 10 125-140. (doi:10.1159/000046880)

Di Meo S, Reed TT, Venditti P \& Victor MV 2016 Role of ROS and RNS sources in physiological and pathological conditions. Oxidative Medicine and Cellular Longevity 2016 1-44 (doi:10.1155/2016/1245049)

Diamond-Stanic MK \& Henriksen EJ 2010 Direct inhibition by angiotensin II of insulin-dependent glucose transport activity in mammalian skeletal muscle involves a ROS-dependent mechanism. Archives of Physiology and Biochemistry 116 88-95. (doi:10.3109/13813451003758703)

Dikalov S 2011 Cross talk between mitochondria and NADPH oxidases. Free Radical Biology and Medicine 51 1289-1301. (doi:10.1016/j. freeradbiomed.2011.06.033)

Dokken BB, Saengsirisuwan V, Kim JS, Teachey MK \& Henriksen EJ 2008 Oxidative stress induced insulin resistance in rat skeletal muscle: role of glycogen synthase kinase-3. American Journal of Physiology 294 E615-E621. (doi:10.1152/ajpendo.00578.2007)

Doughan AK, Harrison DG \& Dikalov SI 2008 Molecular mechanisms of angiotensin II-mediated mitochondrial dysfunction: linking mitochondrial oxidative damage and vascular endothelial dysfunction. Circulation Research 102 488-496. (doi:10.1161/ CIRCRESAHA.107.162800)

Elchebly M, Payette P, Michaliszyn E, Cromlish W, Collins S, Loy AL, Normandin D, Cheng A, Himms-Hagen J, Chan CC, et al. 1999 Increased insulin sensitivity and obesity resistance in mice lacking the protein tyrosine phosphatase-1B gene. Science 283 1544-1548. (doi:10.1126/science.283.5407.1544)

Eldar-Finkelman H, Schreyer SA, Shinohara MM, LeBoeuf RC \& Krebs EG 1999 Increased glycogen synthase kinase-3 activity in diabetes- and obesity-prone C57BL/6J mice. Diabetes 48 1662-1666. (doi:10.2337/ diabetes.48.8.1662)

Engeli S, Bohnke J, Gorzelniak K, Janke J, Schling P, Bader M, Luft FC \& Sharma AM 2005 Weight loss and the renin-angiotensin- aldosterone system. Hypertension 45 356-362. (doi:10.1161/01. HYP.0000154361.47683.d3)

Ernster L \& Lee C-P 1967 Energy-linked reduction of NAD+ by succinate. Methods in Enzymology 10 729-738. (doi:10.1016/00766879(67)10120-1)

Espinosa A, Garcia A, Hartel S, Hidalgo C \& Jaimovich E 2009 NADPH oxidase and hydrogen peroxide mediate insulin-induced calcium increase in skeletal muscle cells. Journal of Biological Chemistry $\mathbf{2 8 4}$ 2568-2575. (doi:10.1074/jbc.M804249200)

Evans JL, Goldfine ID, Maddux BA \& Grodsky GM 2002 Oxidative stress and stress-activated signaling pathways: a unifying hypothesis of type 2 diabetes. Endocrine Reviews 23 599-622. (doi:10.1210/er.2001-0039)

Evans JL, Maddux BA \& Goldfine ID 2005 The molecular basis for oxidative stress-induced insulin resistance. Antioxidant and Redox Signaling 7 1040-1052. (doi:10.1089/ars.2005.7.1040)

Fan X, Rajaa Hussien R \& Brooks GA $2010 \mathrm{H}_{2} \mathrm{O}_{2}$-induced mitochondrial fragmentation in C2C12 myocytes. Free Radical Biology and Medicine 49 1646-1654. (doi:10.1016/j.freeradbiomed.2010.08.024)

Finkel T \& Holbrook NJ 2000 Oxidants, oxidative stress and the biology of ageing. Nature 408 239-247. (doi:10.1038/35041687)

Fisher-Wellman KH \& Neufer PD 2012 Linking mitochondrial bioenergetics to the etiology of insulin resistance via redox biology. Trends in Endocrinology and Metabolism 23 142-153. (doi:10.1016/j. tem.2011.12.008)

Fisher-Wellman KH, Weber TM, Cathey BL, Brophy PM, Gilliam LA, Kane CL, Maples JM, Gavin TP, Houmard JA \& Neufer PD 2014 Mitochondrial respiratory capacity and content are normal in young insulin-resistant obese humans. Diabetes 63 132-141. (doi:10.2337/ db13-0940)

Fleischman A, Kron M, Systrom DM, Hrovat M \& Grinspoon SK 2009 Mitochondrial function and insulin resistance in overweight and normal-weight children. Journal of Clinical Endocrinology \& Metabolism 94 4923-4930. (doi:10.1210/jc.2009-1590)

Folli F, Kahn CR, Hansen H, Bouchie JL \& Feener EP 1997 Angiotensin II inhibits insulin signaling in aortic smooth muscle cells at multiple levels - a potential role for serine phosphorylation in insulin/ angiotensin II crosstalk. Journal of Clinical Investigation $\mathbf{1 0 0}$ 2158-2169. (doi:10.1172/JCI119752)

Forman HJ \& Fridovich I 1973 Superoxide dismutase: a comparison of rate constants. Archives of Biochemistry and Biophysics 158 396-400. (doi:10.1016/0003-9861(73)90636-X)

Forman HJ, Maiorino M \& Ursini F 2010 Signaling functions of reactive oxygen species. Biochemistry 49 835-842. (doi:10.1021/bi9020378)

Frazier AE, Kiu C, Stojanovski D, Hoogenraad NJ \& Ryan MT 2006 Mitochondrial morphology and distribution in mammalian cells. Journal of Biological Chemistry 387 1551-1558. (doi:10.1515/ bc.2006.193)

Fridovich I 1995 Superoxide radical and superoxide dismutases. Annual Review of Biochemistry 64 97-112. (doi:10.1146/annurev. bi.64.070195.000525)

Fueger PT, Bracy DP, Malabanan CM, Pencek RR, Granner DK \& Wasserman DH 2004 Hexokinase II overexpression improves exercise-stimulated but not insulin stimulated muscle glucose uptake in high-fat-fed C57BL/6J mice. Diabetes 53 306-314. (doi:10.2337/ diabetes.53.2.306)

Furler SM, Oakes ND, Watkinson AL \& Kraegen EW 1997 A high-fat diet influences insulin-stimulated post transport muscle glucose metabolism in rats. Metabolism 46 1101-1106. (doi:10.1016/S00260495(97)90286-9)

Gao ZG, Hwang D, Bataille F, Lefevre M, York D, Quon M \& Ye J 2002 Serine phosphorylation of insulin receptor substrate 1 by inhibitor kappa B kinase complex. Journal of Biological Chemistry 27748115 48121. (doi:10.1074/jbc.M209459200)

Garlid KD \& Beavis AD 1986 Evidence for the existence of an inner membrane anion channel in mitochondria. Biochimica et Biophysica Acta 853 187-204. (doi:10.1016/0304-4173(87)90001-2) 
Gerich JE 2003 Clinical significance, pathogenesis, and management of postprandial hyperglycemia. Archives of Internal Medicine 163 1306-1316. (doi:10.1001/archinte.163.11.1306)

Gertz M, Fischer F, Wolters D \& Steegborn C 2008 Activation of the lifespan regulator p66Shc through reversible disulfide bond formation. PNAS 105 5705-5709. (doi:10.1073/pnas.0800691105)

Giorgio M, Migliaccio E, Orsini F, Paolucci D, Moroni M, Contursi C, Pelliccia G, Luzi L, Minucci S, Marcaccio M, et al. 2005 Electron transfer between cytochrome $\mathrm{c}$ and p66Shc generates reactive oxygen species that trigger mitochondrial apoptosis. Cell 122 221-233. (doi:10.1016/j.cell.2005.05.011)

Gomes AP, Duarte FV, Nunes P, Hubbard BP, Teodoro JS, Varela AT, Jones JG, Sinclair DA, Palmeira CM \& Rolo AP 2012 Berberine protects against high fat diet-induced dysfunction in muscle mitochondria by inducing SIRT1-dependent mitochondrial biogenesis. Biochimica et Biophysica Acta 1822 185-195. (doi:10.1016/j.bbadis.2011.10.008)

Gómez-Pérez Y, Capllonch-Amer G, Gianotti M, Lladó I \& Proenza AM 2012 Long-term high-fat-diet feeding induces skeletal muscle mitochondrial biogenesis in rats in a sex-dependent and muscle-type specific manner. Nutrition and Metabolism 9 15. (doi:10.1186/17437075-9-15)

Goodyear LJ, Giorgino F, Sherman LA, Carey J, Smith RJ \& Dohm GL 1995 Insulin-receptor phosphorylation, insulin-receptor substrate-1 phosphorylation, and phosphatidylinositol 3-kinase activity are decreased in intact skeletal-muscle strips from obese subjects. Journal of Clinical Investigation 95 2195-2204. (doi:10.1172/JCI117909)

Goossens GH, Jocken JW, Blaak EE, Schiffers PM, Saris WH \& van Baak MA 2007 Endocrine role of the renin-angiotensin system in human adipose tissue and muscle: effect of $\beta$-adrenergic stimulation. Hypertension 49 542-547. (doi:10.1161/01.HYP.0000256091.55393.92)

Gorzelniak K, Engeli S, Janke J, Luft FC \& Sharma AM 2002 Hormonal regulation of the human adipose-tissue renin-angiotensin system: relationship to obesity and hypertension. Journal of Hypertension $\mathbf{2 0}$ 965-973. (doi:10.1097/00004872-200205000-00032)

Halliwell B \& Gutteridge JMC 2015 Free Radicals in Biology and Medicine. Oxford, UK: Oxford University Press.

Halseth AE, Bracy DP \& Wasserman DH 2000 Limitations to basal and insulin-stimulated skeletal muscle glucose uptake in the high-fat-fed rat. American Journal of Physiology 279 E1064-E1071.

Hancock CR, Han DH, Chen M, Terada S, Yasuda T, Wright DC \& Holloszy JO 2008 High-fat diets cause insulin resistance despite an increase in muscle mitochondria. PNAS 105 7815-7820. (doi:10.1073/pnas.0802057105)

Handy DE \& Loscalzo J 2012 Redox regulation of mitochondrial function. Antioxidant and Redox Signaling 16 1323-1367. (doi:10.1089/ ars.2011.4123)

He F \& Zuo L 2015 Redox roles of reactive oxygen species in cardiovascular diseases. International Journal of Molecular Sciences 16 27770-27780. (doi:10.3390/ijms161126059)

Heilbronn LK, Gan SK, Turner N, Campbell LV \& Chisholm DJ 2007 Markers of mitochondrial biogenesis and metabolism are lower in overweight and obese insulin-resistant subjects. Journal of Clinical Endocrinology and Metabolism 92 1467-1473. (doi:10.1210/jc.2006-2210)

Henriksen EJ, Diamond-Stanic MK \& Marchionne EM 2011. Oxidative stress and the etiology of insulin resistance and type 2 diabetes. Free Radical Biology and Medicine 51 993-999. (doi:10.1016/j. freeradbiomed.2010.12.005)

Hidalgo C, Sánchez G, Barrientos G \& Aracena-Parks P 2006 A transverse tubule NADPH oxidase activity stimulates calcium release from isolated triads via ryanodine receptor type $1 \mathrm{~S}$-glutathionylation. Journal of Biological Chemistry 281 26473-26482. (doi:10.1074/jbc. M600451200)

Hirabara SM, Curi R \& Maechler P 2010 Saturated fatty acid-induced insulin resistance is associated with mitochondrial dysfunction in skeletal muscle cells. Journal of Cellular Physiology 222 187-194. (doi:10.1002/jcp.21936)
Hirosumi J, Tuncman G, Chang L, Gorgun CZ, Uysal KT, Maeda K, Karin M \& Hotamisligil GS 2002 A central role for JNK in obesity and insulin resistance. Nature 420 333-336. (doi:10.1038/nature01137)

Hoehn KL, Hohnen-Behrens C, Cederberg A, Wu LE, Turner N, Yuasa T, Ebina Y \& James DE 2008 IRS1-independent defects define major nodes of insulin resistance. Cell Metabolism 7 421-433. (doi:10.1016/j. cmet.2008.04.005)

Hoehn KL, Salmon AB, Hohnen-Behrens C, Turner N, Hoy AJ, Maghzal GJ, Stocker R, Van Remmen H, Kraegen EW, Cooney GJ, et al. 2009 Insulin resistance is a cellular antioxidant defense mechanism. PNAS 106 17787-17792. (doi:10.1073/ pnas.0902380106)

Hoeks J, Briede JJ, de Vogel J, Schaart G, Nabben M, Moonen-Kornips E, Hesselink MK \& Schrauwen P 2008 Mitochondrial function, content and ROS production in rat skeletal muscle: effect of high-fat feeding. FEBS Letters 582 510-516. (doi:10.1016/j.febslet.2008.01.013)

Hoeks J, van Herpen NA, Mensink M, Moonen-Kornips E, van Beurden D, Hesselink MK \& Schrauwen P 2010 Prolonged fasting identifies skeletal muscle mitochondrial dysfunction as consequence rather than cause of human insulin resistance. Diabetes 59 2117-2125. (doi:10.2337/db10-0519)

Holloway GP, Thrush AB, Heigenhauser GJ, Tandon NN, Dyck DJ, Bonen A \& Spriet LL 2007 Skeletal muscle mitochondrial FAT/CD36 content and palmitate oxidation are not decreased in obese women. American Journal of Physiology: Endocrinology and Metabolism 292 E1782-E1789. (doi:10.1152/ajpendo.00639.2006)

Holmström MH, Iglesias-Gutierrez E, Zierath JR \& Garcia-Roves PM 2012 Tissue-specific control of mitochondrial respiration in obesity-related insulin resistance and diabetes. American Journal of Physiology 302 E731-E739. (doi:10.1152/ajpendo.00159.2011)

Hotamisligil GS, Shargill NS \& Spiegelman BM 1993 Adipose expression of tumor necrosis factor- $\alpha$ : direct role in obesity-linked insulin resistance. Science 259 87-91. (doi:10.1126/science.7678183)

Houstis N, Rosen ED \& Lander ES 2006 Reactive oxygen species have a causal role in multiple forms of insulin resistance. Nature $\mathbf{4 4 0}$ 944-948. (doi:10.1038/nature04634)

Ignarro LJ, Buga GM, Wood KS, Byrns RE \& Chaudhuri G 1987 Endothelium-derived relaxing factor produced and released from artery and vein is nitric oxide. PNAS $\mathbf{8 4}$ 9265-9269. (doi:10.1073/ pnas.84.24.9265)

Iwakami S, Misu H, Takeda T, Sugimori M, Matsugo S, Kaneko S \& Takamura T 2011 Concentration-dependent dual effects of hydrogen peroxide on insulin signal transduction in H4IIEC hepatocytes. PLoS ONE 6 e27401. (doi:10.1371/journal.pone.0027401)

Jastroch M, Divakaruni AS, Mookerjee S, Treberg JR \& Brand MD 2010 Mitochondrial proton and electron leaks. Essays in Biochemistry $\mathbf{4 7}$ 53-67. (doi:10.1042/bse0470053)

Javesghani D, Magder SA, Barreiro E, Quinn MT \& Hussain SN 2002 Molecular characterization of a superoxide generating $\mathrm{NAD}(\mathrm{P}) \mathrm{H}$ oxidase in the ventilatory muscles. American Journal of Respiratory and Critical Care Medicine 165 412-418. (doi:10.1164/ ajrccm.165.3.2103028)

Jensen PK 1966 Antimycin-insensitive oxidation of succinate and reduced nicotinamide-adenine dinucleotide in electron transport particles. I. pH dependency and hydrogen peroxide formation. Biochimica et Biophysica Acta 122 157-166. (doi:10.1016/09266593(66)90057-9)

Jheng HF, Tsai PJ, Guo SM, Kuo LH, Chang CS, Su IJ, Chang CR \& Tsai YS 2012 Mitochondrial fission contributes to mitochondrial dysfunction and insulin resistance in skeletal muscle. Molecular and Cellular Biology 32 309-319. (doi:10.1128/MCB.05603-11)

Jing E, Emanuelli B, Hirschey MD, Boucher J, Lee KY, Lombard D, Verdin EM \& Kahn CR 2011 Sirtuin-3 (Sirt3) regulates skeletal muscle metabolism and insulin signaling via altered mitochondrial oxidation and reactive oxygen species production. PNAS 108 14608-14613. (doi:10.1073/pnas.1111308108) 
Kalupahana NS \& Moustaid-Moussa N 2011 The renin-angiotensin system: a link between obesity, inflammation and insulin resistance. Obesity Reviews 13 136-149. (doi:10.1111/j.1467-789X.2011.00942.x)

Kamata H, Manabe T, Oka S, Kamata K \& Hirata H 2002 Hydrogen peroxide activates IкB kinases through phosphorylation of serine residues in the activation loops. FEBS Letters 519 231-237. (doi:10.1016/S0014-5793(02)02712-6)

Kaneto H, Nakatani Y, Miyatsuka T, Kawamori D, Matsuoka TA, Matsuhisa M, Kajimoto Y, Ichijo H, Yamasaki Y \& Hori M 2004 Possible novel therapy for diabetes with cell-permeable JNK-inhibitory peptide. Nature Medicine 10 1128-1132. (doi:10.1038/nm1111)

Karakelides H, Irving BA, Short KR, O’Brien P \& Nair KS 2010 Age, obesity, and sex effects on insulin sensitivity and skeletal muscle mitochondrial function. Diabetes 59 89-97. (doi:10.2337/db09-0591)

Katsuyama M 2010 NOX/NADPH oxidase, the superoxide-generating enzyme: its transcriptional regulation and physiological roles. Journal of Pharmacological Sciences 114 134-146. (doi:10.1254/jphs.10R01CR)

Kelley DE, Goodpaster B, Wing RR \& Simoneau JA 1999 Skeletal muscle fatty acid metabolism in association with insulin resistance, obesity, and weight loss. American Journal of Physiology 277 E1130-E1141.

Kelley DE, He J, Menshikova EV \& Ritov VB 2002 Dysfunction of mitochondria in human skeletal muscle in type 2 diabetes. Diabetes 51 2944-2950. (doi:10.2337/diabetes.51.10.2944)

Kim YB, Nikoulina SE, Ciaraldi TP, Henry RR \& Kahn BB 1999 Normal insulin-dependent activation of Akt/protein kinase B, with diminished activation of phosphoinositide 3-kinase, in muscle in type 2 diabetes. Journal of Clinical Investigation 104 733-741. (doi:10.1172/JCI6928)

Kim YB, Kotani K, Ciaraldi TP, Henry RR \& Kahn BB 2003 Insulinstimulated protein kinase $\mathrm{C}$ lambda/zeta activity is reduced in skeletal muscle of humans with obesity and type 2 diabetes - reversal with weight reduction. Diabetes 52 1935-1942. (doi:10.2337/ diabetes.52.8.1935)

Kim S, Soltani-Bejnood M, Quignard-Boulange A, Massiera F, Teboul M, Ailhaud G, Kim JH, Moustaid-Moussa N \& Voy BH 2006 The adipose rennin-angiotensin system modulates systemic markers of insulin sensitivity and activates the intrarenal renin-angiotensin system. Journal of Biomedicine and Biotechnology 2006 27012. (doi:10.1155/ jbb/2006/27012)

Knowles RG \& Moncada S 1994 Nitric oxide synthases in mammals. Biochemical Journal 298 249-258. (doi:10.1042/bj2980249)

Kohn AD, Summers SA, Birnbaum MJ \& Roth RA 1996 Expression of a constitutively active Akt Ser/Thr kinase in 3T3-L1 adipocytes stimulates glucose uptake and glucose transporter 4 translocation. Journal of Biological Chemistry 271 31372-31378. (doi:10.1074/ jbc.271.49.31372)

Koves TR, Ussher JR, Noland RC, Slentz D, Mosedale M, Ilkayeva O, Bain J, Stevens R, Dyck JR Newgard CB, et al. 2008 Mitochondrial overload and incomplete fatty acid oxidation contribute to skeletal muscle insulin resistance. Cell Metabolism 7 45-56. (doi:10.1016/j. cmet.2007.10.013)

Kraus RM, Houmard JA, Kraus WE, Tanner CJ, Pierce JR, Choi MD \& Hickner RC 2012 Obesity, insulin resistance, and skeletal muscle nitric oxide synthase. Journal of Applied Physiology 113 758-765. (doi:10.1152/japplphysiol.01018.2011)

Kruszynska YT, Mulford MI, Baloga J, Yu JG \& Olefsky JM 1998 Regulation of skeletal muscle hexokinase II by insulin in nondiabetic and NIDDM subjects. Diabetes 47 1107-1113. (doi:10.2337/ diabetes.47.7.1107)

Lark DS, Fisher-Wellman KH \& Neufer PD 2012 High-fat load: mechanism(s) of insulin resistance in skeletal muscle. International Journal of Obesity 2 S31-S36. (doi:10.1038/ijosup.2012.20)

Lark DS, Kang L, Lustig ME, Bonner JS, James FD, Neufer PD \& Wasserman DH 2015 Enhanced mitochondrial superoxide scavenging does not improve muscle insulin action in the high fat-fed mouse. PLOS ONE 10 e0126732. (doi:10.1371/journal.pone.0126732)
Laurent D, Yerby B, Deacon R \& Gao J 2007 Diet-induced modulation of mitochondrial activity in rat muscle. American Journal of Physiology 293 E1169-E1177. (doi:10.1152/ajpendo.00263.2007)

Leahy JL 2005 Pathogenesis of type 2 diabetes mellitus. Archives of Medical Research 36 197-209. (doi:10.1016/j.arcmed.2005.01.003)

Lee H-Y, Choi CS, Birkenfeld AL, Alves TC, Jornayvaz FR, Jurczak MJ, Zhang D, Woo DK, Shadel GS, Ladiges W, et al. 2010 Targeted expression of catalase to mitochondria prevents age-associated reductions in mitochondrial function and insulin resistance. Cell Metabolism 12 668-674. (doi:10.1016/j.cmet.2010.11.004)

Lefort N, Glancy B, Bowen B, Willis WT, Bailowitz Z, De Filippis EA, Brophy C, Meyer C, Højlund K, Yi Z, et al. 2010 Increased reactive oxygen species production and lower abundance of complex I subunits and carnitine palmitoyltransferase $1 \mathrm{~B}$ protein despite normal mitochondrial respiration in insulin-resistant human skeletal muscle. Diabetes 59 2444-2452. (doi:10.2337/db10-0174)

Li JP, DeFea K \& Roth RA 1999 Modulation of insulin receptor substrate-1 tyrosine phosphorylation by an Akt/phosphatidylinositol 3-kinase pathway. Journal of Biological Chemistry 274 9351-9356. (doi:10.1074/ jbc.274.14.9351)

Li Y, Mouche S, Sajic T, Veyrat-Durebex C, Supale R, Pierroz D, Ferrari S, Negro F, Hasler U, Feraille E, et al. 2012 Deficiency in the NADPH oxidase 4 predisposes towards diet-induced obesity. International Journal of Obesity 36 1503-1513. (doi:10.1038/ijo.2011.279)

Liesa M, Palacín M \& Zorzano A 2009 Mitochondrial dynamics in mammalian health and disease. Physiological Reviews 89 799-845. (doi:10.1152/physrev.00030.2008)

Liochev SI \& Fridovich I 2007 The effects of superoxide dismutase on $\mathrm{H}_{2} \mathrm{O}_{2}$ formation. Free Radical Biology and Medicine 10 1465-1469. (doi:10.1016/j.freeradbiomed.2007.02.015)

Lionetti L, Mollica MP, Crescenzo R, D’Andrea E, Ferraro M, Bianco F, Liverini G \& Iossa S 2007 Skeletal muscle subsarcolemmal mitochondrial dysfunction in high-fat fed rats exhibiting impaired glucose homeostasis. International Journal of Obesity 31 1596-1604. (doi:10.1038/sj.ijo.0803636)

Loh K, Deng H, Fukushima A, Cai X, Boivin B, Galic S, Bruce C, Shields BJ, Skiba B, Ooms LM, et al. 2009 Reactive oxygen species enhance insulin sensitivity. Cell Metabolism 10 260-272. (doi:10.1016/j.cmet.2009.08.009)

Loschen G, Azzi A, Richter R \& Flohé L 1974 Superoxide radicals as precursors of mitochondrial hydrogen peroxide. FEBS Letters $\mathbf{4 2}$ 68-72. (doi:10.1016/0014-5793(74)80281-4)

Lowell BB \& Shulman GI 2005 Mitochondrial dysfunction and type 2 diabete. Science 307 384-387. (doi:10.1126/science.1104343)

Macconi D, Perico L, Longaretti L, Morigi M, Cassis P, Buelli S, Perico N, Remuzzi G \& Benigni A 2015 Sirtuin3 dysfunction is the key determinant of skeletal muscle insulin resistance by angiotensin II. PLOS ONE 10 e0127172. (doi:10.1371/journal.pone.0127172)

Matsuzawa Y, Funahashi T \& Nakamura T 1999 Molecular mechanism of metabolic syndrome $\mathrm{X}$ : contribution of adipocytokines adipocytederived bioactive substances. Annals of the New York Academy of Sciences 892 146-154. (doi:10.1111/j.1749-6632.1999.tb07793.x)

May JM \& de Haen C 1979 Insulin-stimulated intracellular hydrogen peroxide production in rat epididymal fat cells. Journal of Biological Chemistry 254 2214-2220.

McCormack JG, Halestrap AP \& Denton RM 1990 Role of calcium ions in regulation of mammalian intramitochondrial metabolism. Physiological Reviews 70 391-425.

Migliaccio E, Giorgio M, Mele S, Pelicci G, Reboldi P, Pandolfi PP, Lanfrancone L \& Pelicci PG 1999 The p66(shc) adaptor protein controls oxidative stress response and life span in mammals. Nature 402 309-313. (doi:10.1038/46311)

Mitchell P \& Moyle J 1965 Stoichiometry of proton translocation through the respiratory chain and adenosine triphosphatase systems of rat liver mitochondria. Nature 208 147-151. (doi:10.1038/208147a0) http://joe.endocrinology-journals.org

DOI: $10.1530 / \mathrm{JOE}-16-0598$
(C) 2017 Society for Endocrinology Printed in Great Britain 
Mitsuishi M, Miyashita K, Muraki A \& Itoh H 2009 Angiotensin II reduces mitochondrial content in skeletal muscle and affects glycemic control. Diabetes 58 710-717. (doi:10.2337/db08-0949)

Mofarrahi M, Brandes RP, Gorlach A, Hanze J, Terada LS, Quinn MT, Mayaki D, Petrof B \& Hussain SN 2008 Regulation of proliferation of skeletal muscle precursor cells by NADPH oxidase. Antioxidants and Redox Signaling 10 559-574. (doi:10.1089/ars.2007.1792)

Moncada S \& Erusalimsky JD 2002 Does nitric oxide modulate mitochondrial energy generation and apoptosis? Nature Reviews Molecular Cell Biology 3 214-220. (doi:10.1038/nrm762)

Mootha VK, Lindgren CM, Eriksson KF, Subramanian A, Sihag S, Lehar J, Puigserver P, Carlsson E, Ridderstråle M, Laurila E, et al. 2003 PGC$1 \alpha$-responsive genes involved in oxidative phosphorylation are coordinately downregulated in human diabetes. Nature Genetics $\mathbf{3 4}$ 267-273. (doi:10.1038/ng1180)

Muller FL, Liu Y \& Van Remmen H 2004 Complex III releases superoxide to both sides of the inner mitochondrial membrane. Journal of Biological Chemistry 279 49064-49073. (doi:10.1074/jbc.M407715200)

Muller FL, Lustgarten MS, Jang Y, Richardson A \& Van Remmen H 2007 Trends in oxidative aging theories. Free Radical Biology and Medicine 43 477-503. (doi:10.1016/j.freeradbiomed.2007.03.034)

Muoio DM \& Neufer PD 2012 Lipid-induced mitochondrial stress and insulin action in muscle. Cell Metabolism 15 595-605. (doi:10.1016/j. cmet.2012.04.010)

Nathan C \& Xie Q-W 1994 Nitric oxide synthases: roles, tolls, and controls. Cell 78 915-918. (doi:10.1016/0092-8674(94)90266-6)

Navarro A \& Boveris A 2007 The mitochondrial energy transduction system and the aging process. American Journal of Physiology 292 C670-C686. (doi:10.1152/ajpcell.00213.2006)

Nemoto S, Combs CA, French S, Ahn BH, Fergusson MM, Balaban RS \& Finkel T 2006 The mammalian longevity-associated gene product p66shc regulates mitochondrial metabolism. Journal of Biological Chemistry 281 10555-10560. (doi:10.1074/jbc.M511626200)

Newsholme P, Haber EP, Hirabara SM, Rebelato EL, Procopio J, Morgan D, Oliveira-Emilio HC, Carpinelli AR \& Curi R 2007 Diabetes associated cell stress and dysfunction: role of mitochondrial and nonmitochondrial ROS production and activity. Journal of Physiology $\mathbf{5 8 3}$ 9-24. (doi:10.1113/jphysiol.2007.135871)

Nunnari J \& Suomalainen A 2012 Mitochondria: in sickness and in health. Cell 148 1145-1159. (doi:10.1016/j.cell.2012.02.035)

Nunnari J, Wong ED, Meeusen S \& Wagner JA 2002 Studying the behavior of mitochondria. Methods in Enzymology 351 381-393. (doi: 10.1038/208147a0)

Ogihara T, Asano T, Ando K, Chiba Y, Sakoda H, Anai M, Shojima N, Ono H, Onishi Y, Fujishiro M, et al. 2002 Angiotensin II-induced insulin resistance is associated with enhanced insulin signaling. Hypertension 40 872-879. (doi:10.1161/01.HYP.0000040262.48405.A8)

Okado-Matsumoto A \& Fridovich I 2001 Subcellular distribution of superoxide dismutases (SOD) in rat liver: $\mathrm{Cu}, \mathrm{Zn}-\mathrm{SOD}$ in mitochondria. Journal of Biological Chemistry 276 38388-38393. (doi:10.1074/jbc.M105395200)

Okamoto Y, Kihara S, Ouchi N, Nishida M, Arita Y, Kumada M, Ohashi K, Sakai N, Shimomura I, Kobayashi H, Terasaka N, et al. 2002 Adiponectin reduces atherosclerosis in apolipoprotein E-deficient mice. Circulation 106 2767-2770. (doi:10.1161/01. CIR.0000042707.50032.19)

Otto TC \& Lane MD 2005 Adipose development: from stem cell to adipocyte. Critical Reviews in Biochemistry and Molecular Biology $\mathbf{4 0}$ 229-242. (doi:10.1080/10409230591008189)

Pacher P, Beckman JS \& Liaudet L 2007 Nitric oxide and peroxynitrite in health and disease. Physiological Reviews 87 315-424. (doi:10.1152/ physrev.00029.2006)

Palmer CS, Osellame LD, Stojanovski D \& Ryan MT 2011 The regulation of mitochondrial morphology: intricate mechanisms and dynamic machinery. Cellular Signalling 23 1534-1545. (doi:10.1016/j. cellsig.2011.05.021)
Pastorino JG, Hoek JB \& Shulga N 2005 Activation of glycogen synthase kinase $3 \beta$ disrupts the binding of hexokinase II to mitochondria by phosphorylating voltage-dependent anion channel and potentiates chemotherapy-induced cytotoxicity. Cancer Research 65 10545-10554. (doi:10.1158/0008-5472.CAN-05-1925)

Patti ME, Butte AJ, Crunkhorn S, Cusi K, Berria R, Kashyap S, Miyazaki Y, Kohane I \& Costello M 2003 Coordinated reduction of genes of oxidative metabolism in humans with insulin resistance and diabetes: potential role of PGC-1 and NRF1. PNAS 100 8466-8471. (doi:10.1073/pnas.1032913100)

Paz K, Hemi R, LeRoith D, Karasik A, Elhanany E, Kanety H \& Zick Y 1997 Elevated serine/threonine phosphorylation of IRS-1 and IRS-2 inhibits their binding to the juxtamembrane region of the insulin receptor and impairs their ability to undergo insulin-induced tyrosine phosphorylation. Journal of Biological Chemistry 272 29911-29918. (doi:10.1074/jbc.272.47.29911)

Pearce NJ, Arch JR, Clapham JC, Coghlan MP, Corcoran SL, Lister CA, Llano A, Moore GB, Murphy GJ, Smith SA, et al. 2004 Development of glucose intolerance in male transgenic mice overexpressing human glycogen synthase kinase- $3 \beta$ on a muscle-specific promoter. Metabolism 53 1322-1330. (doi:10.1016/j.metabol.2004.05.008)

Peluso G, Petillo O, Margarucci S, Mingrone G, Greco AV, Indiveri C, Palmieri F, Melone MA, Reda E \& Calvani M 2002 Decreased mitochondrial carnitine translocase in skeletal muscles impairs utilization of fatty acids in insulin-resistant patients. Frontiers in Bioscience 7 a109-a116. (doi:10.2741/A745)

Pendergrass M, Koval J, Vogt C, Yki-Jarvinen H, Iozzo P, Pipek R, Ardehali H, Printz R, Granner D, DeFronzo RA, et al. 1998 Insulin induced hexokinase II expression is reduced in obesity and NIDDM. Diabetes 47 387-394. (doi:10.2337/diabetes.47.3.387)

Perreault M \& Marette A 2001 Targeted disruption of inducible nitric oxide synthase protects against obesity-linked insulin resistance in muscle. Nature Medicine 7 1138-1143. (doi:10.1038/nm1001-1138)

Petersen KF, Dufour S, Befroy D, Garcia R \& Shulman GI 2004 Impaired mitochondrial activity in the insulin-resistant offspring of patients with type 2 diabetes. New England Journal of Medicine 350 664-671. (doi:10.1056/NEJMoa031314)

Phielix E, Schrauwen-Hinderling VB, Mensink M, Lenaers E, Meex R, Hoeks J, Kooi ME, Moonen-Kornips E, Sels JP, et al. 2008 Lower intrinsic ADP-stimulated mitochondrial respiration underlies in vivo mitochondrial dysfunction in muscle of male type 2 diabetic patients. Diabetes 57 2943-2949. (doi:10.2337/db08-0391)

Pilon G, Charbonneau A, White PJ, Dallaire P, Perreault M, Kapur S \& Marette A 2010 Endotoxin mediated-iNOS induction causes insulin resistance via ONOO- induced tyrosine nitration of IRS-1 in skeletal muscle. PLOS ONE 5 e15912. (doi:10.1371/journal.pone.0015912)

Qiu X, Brown K, Hirschey MD, Verdin E \& Chen D 2010 Calorie restriction reduces oxidative stress by SIRT3-mediated SOD2 activation. Cell Metabolism 12 662-667. (doi:10.1016/j. cmet.2010.11.015)

Radi R 2013 Peroxynitrite, a stealthy biological oxidant. Journal of Biological Chemistry 288 26464-26472. (doi:10.1074/jbc. R113.472936)

Radi R, Cassina A, Hodara R, Quijana C \& Castro L 2002 Peroxynitrite reactions and formation in mitochondria. Free Radical Biology and Medicine 33 1451-1464. (doi:10.1016/S0891-5849(02)01111-5)

Randle PJ, Kerbey AL \& Espinal J 1988 Mechanisms decreasing glucose oxidation in diabetes and starvation: role of lipid fuels and hormones. Diabetes/Metabolism Reviews 4 623-638. (doi:10.1002/ dmr.5610040702)

Reed TT 2011 Lipid peroxidation and neurodegenerative disease. Free Radical Biology and Medicine 51 1302-1319. (doi:10.1016/j. freeradbiomed.2011.06.027)

Richey JM, Ader M, Moore D \& Bergman RN 1999 Angiotensin II induces insulin resistance independent of changes in interstitial insulin. American Journal of Physiology 277 E920-E926. 
Rindler PM, Crewe CL, Fernandes J, Kinter M \& Szweda LI 2013 Redox regulation of insulin sensitivity due to enhanced fatty acid utilization in the mitochondria. American Journal of Physiology 305 H634-H643. (doi:10.1152/ajpheart.00799.2012)

Ristow M \& Schmeisser S 2011 Extending life span by increasing oxidative stress. Free Radical Biology and Medicine 51 327-336. (doi:10.1016/j.freeradbiomed.2011.05.010)

Ritov VB, Menshikova EV, He J, Ferrell RE, Goodpaster BH \& Kelley DE 2005 Deficiency of subsarcolemmal mitochondria in obesity and type 2 diabetes. Diabetes 54 8-14. (doi:10.2337/diabetes.54.1.8)

Ritov VB, Menshikova EV, Azuma K, Wood R, Toledo FG, Goodpaster BH, Ruderman NB \& Kelley DE 2010 Deficiency of electron transport chain in human skeletal muscle mitochondria in type 2 diabetes mellitus and obesity. American Journal of Physiology 298 E49-E58. (doi:10.1152/ajpendo.00317.2009)

Roos G \& Messens J 2011 Protein sulfenic acid formation: from cellular damage to redox regulation. Free Radical Biology and Medicine $\mathbf{5 1}$ 314-326. (doi:10.1016/j.freeradbiomed.2011.04.031)

Sakamoto K \& Holman GD 2008 Emerging role for AS160/TBC1D4 and TBC1D1 in the regulation of GLUT4 traffic. American Journal of Physiology 295 E29-E37. (doi:10.1152/ajpcell.00466.2007)

Sakellariou GK, Vasilaki A, Palomero J, Kayani A, Zibrik L, McArdle A \& Jackson MJ 2013 Studies of mitochondrial and nonmitochondrial sources implicate nicotinamide adenine dinucleotide phosphate oxidase(s) in the increased skeletal muscle superoxide generation that occurs during contractile activity. Antioxidants and Redox Signaling 18 603-621. (doi:10.1089/ars.2012.4623)

Sakellariou GK, Jackson MJ \& Vasilaki M 2014 Redefining the major contributors to superoxide production in contracting skeletal muscle. The role of NAD(P)H oxidases. Free Radical Research 48 12-29. (doi:10. 3109/10715762.2013.830718)

Samjoo IA, Safdar A, Hamadeh MJ, Glover AW, Mocellin NJ, Santana J, Little JP, Steinberg GR, Raha S \& Tarnopolsky MA 2013 Markers of skeletal muscle mitochondrial function and lipid accumulation are moderately associated with the homeostasis model assessment index of insulin resistance in obese men. PLOS ONE $\mathbf{8}$ e66322. (doi:10.1371/ journal.pone.0066322)

Samocha-Bonet D, Campbell LV, Mori TA, Croft KD, Greenfield JR, Turner N \& Heilbronn LK 2012 Overfeeding reduces insulin sensitivity and increases oxidative stress, without altering markers of mitochondrial content and function in humans. PLOS ONE 7 e36320. (doi:10.1371/journal.pone.0036320)

Schmieder RE, Hilgers KF, Schlaich MP \& Schmidt BM 2007 Reninangiotensin system and cardiovascular risk. Lancet 369 1208-1219. (doi:10.1016/S0140-6736(07)60242-6)

Schoenmakers E, Agostini M, Mitchell C, Schoenmakers N, Papp L, Rajanayagam O, Padidela R, Ceron-Gutierrez L, Doffinger R, Prevosto C, et al. 2010 Mutations in the selenocysteine insertion sequence-binding protein 2 gene lead to a multisystem selenoprotein deficiency disorder in humans. Journal of Clinical Investigation 120 4220-4235. (doi:10.1172/JCI43653)

Schonfeld P \& Wojtczak L 2008 Fatty acids as modulators of the cellular production of reactive oxygen species. Free Radical Biology and Medicine 45 231-241. (doi:10.1016/j.freeradbiomed.2008.04.029)

Schrauwen-Hinderling VB, Kooi ME, Hesselink MK, Jeneson JA, Backes WH, van Echteld CJ, van Engelshoven JM, Mensink M \& Schrauwen P 2007 Impaired in vivo mitochondrial function but similar intramyocellular lipid content in patients with type 2 diabetes mellitus and BMI-matched control subjects. Diabetologia 50 113-120. (doi:10.1007/s00125-006-0475-1)

Sebastián D, Hernández-Alvarez MI, Segalés J, Sorianello E, Muñoz JP, Sala D, Waget A, Liesa M, Paz JC, Gopalacharyulu P, et al. 2012 Mitofusin 2 (Mfn2) links mitochondrial and endoplasmic reticulum function with insulin signaling and is essential for normal glucose homeostasis. PNAS 109 5523-5528. (doi:10.1073/pnas.1108220109)
Seifert EL, Estey C, Xuan JY \& Harper ME 2010 Electron transport chain dependent and -independent mechanisms of mitochondrial $\mathrm{H}_{2} \mathrm{O}_{2}$ emission during long-chain fatty acid oxidation. Journal of Biological Chemistry 285 5748-5758. (doi:10.1074/jbc.M109.026203)

Sethi JK \& Vidal-Puig AJ 2007 Thematic review series: adipocyte biology. Adipose tissue function and plasticity orchestrate nutritional adaptation. Journal of Lipid Research 48 1253-1262. (doi:10.1194/jlr. R700005-JLR200)

Shelley P, Martin-Gronert MS, Rowlerson A, Poston L, Heales SJ, Hargreaves IP, McConnell JM, Ozanne SE \& Fernandez-Twinn DS 2009 Altered skeletal muscle insulin signaling and mitochondrial complex II-III linked activity in adult offspring of obese mice. American Journal of Physiology 297 R675-R681. (doi:10.1152/ ajpregu.00146.2009)

Shimomura I, Funahashi T, Takahashi M, Maeda K, Kotani K, Nakamura T, Yamashita S, Miura M, Fukuda Y, Takemura K, et al. 1996 Enhanced expression of PAI-1 in visceral fat: possible contributor to vascular disease in obesity. Nature Medicine 2 800-803. (doi:10.1038/ nm0796-800)

Shiuchi T, Iwai M, Li HS, Wu L, Min LJ, Li JM, Okumura M, Cui TX \& Horiuchi M 2004 Angiotensin II type-1 receptor blocker valsartan enhances insulin sensitivity in skeletal muscles of diabetic mice. Hypertension 43 1003-1010. (doi:10.1161/01. HYP.0000125142.41703.64)

Shulman GI 2000 Cellular mechanisms of insulin resistance. Journal of Clinical Investigation 106 171-176. (doi:10.1172/JCI10583)

Sies H 1997 Oxidative stress: oxidants and antioxidants. Experimental Physiology 82 291-295. (doi:10.1113/expphysiol.1997.sp004024)

Simoneau J-A, Veerkamp JH, Turcotte LP \& Kelley DE 1999 Markers of capacity to utilize fatty acids in human skeletal muscle: relation to insulin resistance and obesity and effects of weight loss. FASEB Journal 13 2051-2060.

Sleigh A, Raymond-Barker P, Thackray K, Porter D, Hatunic M, Vottero A, Burren C, Mitchell C, McIntyre M, Brage S, et al. 2011 Mitochondrial dysfunction in patients with primary congenital insulin resistance. Journal of Clinical Investigation 121 2457-2461. (doi:10.1172/JCI46405)

Soliman MA, Abdel Rahman AM, Lamming DW, Birsoy K, Pawling J, Frigolet ME, Lu H, Fantus IG, Pasculescu A, Zheng Y, et al. 2014 The adaptor protein p66Shc inhibits mTOR-dependent anabolic metabolism. Science Signaling 7 ra17. (doi:10.1126/scisignal.2004785)

Someya S, Yu W, Hallows WC, Xu J, Vann JM, Leeuwenburgh C, Tanokura M, Denu JM \& Prolla TA 2010 Sirt3 mediates reduction of oxidative damage and prevention of age-related hearing loss under caloric restriction. Cell 143 802-812. (doi:10.1016/j.cell.2010.10.002)

Sparks LM, Xie H, Koza RA, Mynatt R, Hulver MW, Bray GA \& Smith SR 2005 A high-fat diet coordinately downregulates genes required for mitochondrial oxidative phosphorylation in skeletal muscle. Diabetes 54 1926-1933. (doi:10.2337/diabetes.54.7.1926)

Suh YA, Arnold RS, Lassegue B, Shi J, Xu X, Sorescu D, Chung AB, Griendling KK \& Lambeth JD 1999 Cell transformation by the superoxide-generating oxidase Mox1. Nature 401 79-82. (doi:10.1038/43459)

Szendroedi J, Schmid AI, Chmelik M, Toth C, Brehm A, Krssak M, Nowotny P, Wolzt M, Waldhausl W \& Roden M 2007 Muscle mitochondrial ATP synthesis and glucose transport/phosphorylation in Type 2 diabetes. PLoS Medicine 4 e154. (doi:10.1371/journal. pmed.0040154)

Taddeo EP, Laker RC, Breen DS, Akhtar YN, Kenwood BM, Liao JA, Zhang M, Fazakerley DJ, Tomsig JL, Harris TE, et al. 2014 Opening of the mitochondrial permeability transition pore links mitochondrial dysfunction to insulin resistance in skeletal muscle. Molecular Metabolism 3 124-134. (doi:10.1016/j.molmet.2013.11.003)

Takada S, Kinugawa S, Hirabayashi K, Suga T, Yokota T, Takahashi M, Fukushima A, Homma T, Ono T, Sobirin MA, et al. 2013 Angiotensin II receptor blocker improves the lowered exercise capacity and http://joe.endocrinology-journals.org

DOI: $10.1530 / \mathrm{JOE}-16-0598$
() 2017 Society for Endocrinology Printed in Great Britain 
impaired mitochondrial function of the skeletal muscle in type 2 diabetic mice. Journal of Applied Physiology 114 844-857. (doi:10.1152/japplphysiol.00053.2012)

Teodoro BG, Baraldi FG, Sampaio IH, Bomfim LH, Queiroz AL, Passos MA, Carneiro EM, Alberici LC, Gomis R, Amaral FG, et al. 2014 Melatonin prevents mitochondrial dysfunction and insulin resistance in rat skeletal muscle. Journal of Pineal Research 57 155-167. (doi:10.1111/ jpi.12157)

Tirosh A, Potashnik R, Bashan N \& Rudich A 1999 Oxidative stress disrupts insulin-induced cellular redistribution of insulin receptor substrate-1 and phosphatidylinositol 3-kinase in 3T3-L1 adipocytes. A putative cellular mechanism for impaired protein kinase B activation and GLUT4 translocation. Journal of Biological Chemistry 274 10595-10602. (doi:10.1074/jbc.274.15.10595)

Tomilov AA, Bicocca V, Schoenfeld RA, Giorgio M, Migliaccio E, Ramsey JJ, Hagopian K, Pelicci PG \& Cortopassi GA 2010 Decreased superoxide production in macrophages of long-lived p66Shc knockout mice. Journal of Biological Chemistry 285 1153-1165. (doi:10.1074/ jbc.M109.017491)

Tonks NK 2006 Protein tyrosine phosphatases: from genes, to function, to disease. Nature Reviews Molecular Cell Biology 7 833-846. (doi:10.1038/nrm2039)

Troisi RJ, Weiss ST, Parker DR, Sparrow D, Young JB \& Landsberg L 1991 Relation of obesity and diet to sympathetic nervous system activity. Hypertension 17 669-677. (doi:10.1161/01.HYP.17.5.669)

Turner N, Bruce CR, Beale SM, Hoehn KL, So T, Rolph MS \& Cooney GJ 2007 Excess lipid availability increases mitochondrial fatty acid oxidative capacity in muscle: evidence against a role for reduced fatty acid oxidation in lipid-induced insulin resistance in rodents. Diabetes 56 2085-2092. (doi:10.2337/db07-0093)

Turrens JF \& Boveris AV 1980 Generation of superoxide anion by the NADH dehydrogenase of bovine heart mitochondria. Biochemical Journal 191 421-427. (doi:10.1042/bj1910421)

Uckaya G, Ozata M, Sonmez A, Kinalp C, Eyileten T, Bingol N, Koc B, Kocabalkan F \& Ozdemir IC 1999 Plasma leptin levels strongly correlate with plasma rennin activity in patients with essential hypertension. Hormone and Metabolic Research 31 435-438. (doi:10.1055/s-2007-978769)

Valko M, Leibfritz D, Moncol J, Cronin MT, Mazur M \& Telser J 2007 Free radicals and antioxidants in normal physiological functions and human disease. International Journal of Biochemistry and Cell Biology 39 44-84. (doi:10.1016/j.biocel.2006.07.001)

Vannuvel K, Renard P, Raes M \& Arnould T 2013 Functional and morphological impact of ER stress on mitochondria. Journal of Cellular Physiology 228 1802-1818. (doi:10.1002/jcp.24360)

Venditti P \& Di Meo S 2006 Thyroid hormone-induced oxidative stress. Cellular and Molecular Life Sciences 63 414-434. (doi:10.1007/s00018005-5457-9)

Venditti P, Di Stefano L \& Di Meo S 2013 Mitochondrial metabolism of reactive oxygen species. Mitochondrion 13 71-82. (doi:10.1016/j. mito.2013.01.008)

Venditti P, Napolitano G \& Di Meo S 2015 Role of mitochondria and other ROS sources in hyperthyroidism-linked oxidative stress. Immunology, Endocrine and Metabolic Agents in Medicinal Chemistry 15 5-36. (doi:10.2174/187152221501150710124951)

Vercesi AE, Kowaltowski AJ, Grijalba MT, Meinicke AR \& Castilho RF 1997 The role of reactive oxygen species in mitochondrial permeability transition. Bioscience Reports 17 43-52. (doi:10.102 3/A:1027335217774)

Verdin E, Hirschey MD, Finley LW \& Haigis MC 2010 Sirtuin regulation of mitochondria: energy production, apoptosis, and signaling. Trends in Biochemical Sciences 35 669-675. (doi:10.1016/j.tibs.2010.07.003)

Vettor R, Milan G, Rossato M \& Federspil G 2005 Review article: adipocytokines and insulin resistance. Alimentary Pharmacology and Therapeutics 22 3-10. (doi:10.1111/j.1365-2036.2005.02587.x)
Vieira H \& Kroemer G 2003 Mitochondria as targets of apoptosis regulation by nitric oxide. IUBMB Life 55 613-616. (doi:10.1080/1521 6540310001639652)

Viitanen PV, Geiger PJ, Erickson-Viitanen S \& Bessman SP 1984 Evidence for functional hexokinase compartmentation in rat skeletal muscle mitochondria. Journal of Biological Chemistry 259 9679-9686.

Vogel R, Wiesinger H, Hamprecht B \& Dringen R 1999 The regeneration of reduced glutathione in rat forebrain mitochondria identifies metabolic pathways providing the NADPH required. Neuroscience Letters 275 97-100. (doi:10.1016/S0304-3940(99)00748-X)

Vogt C, Yki-Jarvinen H, Iozzo P, Pipek R, Pendergrass M, Koval J. Ardehali H, Printz R, Granner D, Defronzo R, et al. 1998 Effects of insulin on subcellular localization of hexokinase II in human skeletal muscle in vivo. Journal of Clinical Endocrinology and Metabolism $\mathbf{8 3}$ 230-234. (doi:10.1210/jc.83.1.230)

Vogt C, Ardehali H, Iozzo P, Yki-Jarvinen H, Koval J, Maezono K, Pendergrass M, Printz R, Granner D, DeFronzo R, et al. 2000 Regulation of hexokinase II expression in human skeletal muscle in vivo. Metabolism 49 814-818. (doi:10.1053/meta.2000.6245)

Walker JE, Collinson IR, Van Raaij MJ \& Runswick MJ 1995 Structural analysis of ATP synthase from bovine heart mitochondria. Methods in Enzymology 260 163-190. (doi:10.1016/0076-6879(95)60136-8)

Warren BE \& Lou PH, Lucchinetti E, Zhang L, Clanachan AS, Affolter A, Hersberger M, Zaugg M \& Lemieux H 2014 Early mitochondrial dysfunction in glycolytic muscle, but not oxidative muscle, of the fructose-fed insulin-resistant rat. American Journal of Physiology 306 E658-E667. (doi:10.1152/ajpendo.00511.2013)

Wei Y, Sowers JR, Nistala R, Gong H, Uptergrove G M-E, Clark SE, Morris EM, Szary N, Manrique C \& Stump CS 2006 Angiotensin II-induced NADPH oxidase activation impairs insulin signaling in skeletal muscle cells. Journal of Biological Chemistry 281 35137-35146. (doi:10.1074/jbc.M601320200)

Wei Y, Sowers JR, Clark SE, Li W, Ferrario CM \& Stump CS 2008 Angiotensin II-induced skeletal muscle insulin resistance mediated by NF-kB activation via NADPH oxidase. American Journal of Physiology 294 E345-E351. (doi:10.1152/ajpcell.00216.2007)

Wessels B, van den Broek NM, Ciapaite J, Houten SM, Wanders RJ, Nicolay K \& Prompers JJ 2015 Carnitine supplementation in highfat diet-fed rats does not ameliorate lipid-induced skeletal muscle mitochondrial dysfunction in vivo. American Journal of Physiology 309 E670-E678. (doi:10.1152/ajpendo.00144.2015)

White MF 2002 IRS proteins and the common path to diabetes. American Journal of Physiology 283 E413-E422. (doi:10.1152/ ajpendo.00514.2001)

White MF \& Kahn CR 1994 The insulin signaling system. Journal of Biological Chemistry 269 1-4.

Wijesekara N, Konrad D, Eweida M, Jefferies C, Liadis N, Giacca A, Crackower M, Suzuki A, Mak TW, Kahn CR, et al. 2005 Musclespecific Pten deletion protects against insulin resistance and diabetes. Molecular and Cellular Biology 25 1135-1145. (doi:10.1128/ MCB.25.3.1135-1145.2005)

Winterbourn CC \& Metodiewa D 1995 Reaction of superoxide with glutathione and other thiols. Methods in Enzymology 251 81-86. (doi:10.1016/0076-6879(95)51112-1)

Wredenberg A, Freyer C, Sandström ME, Katz A, Wibom R, Westerblad H \& Larsson NG 2006 Respiratory chain dysfunction in skeletal muscle does not cause insulin resistance. Biochemical and Biophysical Research Communications 350 202-207. (doi:10.1016/j.bbrc.2006.09.029)

Wu Z, Rogers B, Kachi S, Hackett SF, Sick A \& Campochiaro PA 2006 Reduction of p66Shc suppresses oxidative damage in retinal pigmented epithelial cells and retina. Journal of Cellular Physiology 209 996-1005. (doi:10.1002/jcp.20819)

Wu R, Smeele KM, Wyatt E, Ichikawa Y, Eerbeek O, Sun L, Chawla K, Hollmann MW, Nagpal V, Heikkinen S, et al. 2011a Reduction in hexokinase II levels results in decreased cardiac function and altered http://joe.endocrinology-journals.org

DOI: 10.1530/JOE-16-0598
C 2017 Society for Endocrinology Printed in Great Britain 
remodeling after ischemia/reperfusion injury. Circulation Research 108 60-69. (doi:10.1161/CIRCRESAHA.110.223115)

Wu S, Zhou F, Zhang Z \& Xing D $2011 b$ Mitochondrial oxidative stress causes mitochondrial fragmentation via differential modulation of mitochondrial fission-fusion proteins. FEBS Journal 278 941-954. (doi:10.1111/j.1742-4658.2011.08010.x)

Yamada T, Ida T, Yamaoka Y, Ozawa K, Takasan H \& Honjo I 1975 Two distinct patterns of glucose intolerance in icteric rats and rabbits. Relationship to impaired liver mitochondria function. Journal of Laboratory and Clinical Medicine 86 38-45.

Yamauchi T, Kamon J, Minokoshi Y, Ito Y, Waki H, Uchida S, Yamashita S, Noda M, Kita S, Ueki K, et al. 2002 Adiponectin stimulates glucose utilization and fatty-acid oxidation by activating AMP-activated protein kinase. Nature Medicine 8 1288-1295. (doi:10.1038/nm788)

Yang C, Aye CC, Li X, Diaz Ramos A, Zorzano A \& Mora S 2012 Mitochondrial dysfunction in insulin resistance: differential contributions of chronic insulin and saturated fatty acid exposure in muscle cells. Bioscience Reports 32 465-478. (doi:10.1042/ BSR20120034)

Yu BP 1994 Cellular defenses against damage from reactive oxygen species. Physiological Reviews 74 139-162.

Yu T, Sheu SS, Robotham JL \& Yoon Y 2008 Mitochondrial fission mediates high glucose-induced cell death through elevated production of reactive oxygen species. Cardiovascular Research $\mathbf{7 9}$ 341-351. (doi:10.1093/cvr/cvn104)

Yuzefovych LV, Musiyenko SI, Wilson GL \& Rachek LI 2013 Mitochondrial DNA damage and dysfunction, and oxidative stress are associated with endoplasmic reticulum stress, protein degradation and apoptosis in high fat diet-induced insulin resistance mice. PLoS ONE 8 e54059. (doi:10.1371/journal.pone.0054059)

Zhande R, Mitchell JJ, Wu J \& Sun XJ 2002 Molecular mechanism of insulin induced degradation of insulin receptor substrate 1 . Molecular and Cellular Biology 22 1016-1026. (doi:10.1128/ MCB.22.4.1016-1026.2002)

Zierath JR, Krook A \& Wallberg-Henriksson H 2000 Insulin action and insulin resistance in human skeletal muscle. Diabetologia 43 821-835. (doi:10.1007/s001250051457)

Zisman A, Peroni OD, Abel ED, Michael MD, Mauvais-Jarvis F, Lowell BB, Wojtaszewski JF, Hirshman MF, Virkamaki A, Goodyear LJ, et al. 2000 Targeted disruption of the glucose transporter 4 selectively in muscle causes insulin resistance and glucose intolerance. Nature Medicine 6 924-928. (doi:10.1038/78693)

Zorov DB, Filburn CR, Klotz L-O, Zweier JL \& Sollott SJ 2000 Reactive oxygen species (ROS)-induced ROS release: a new phenomenon accompanying induction of the mitochondrial permeability transition in cardiacmyocytes. Journal of Experimental Medicine 192 1001-1014. (doi:10.1084/jem.192.7.1001)

Received in final form 10 January 2017 Accepted 31 January 2017
๑) 2017 Society for Endocrinology Printed in Great Britain
Published by Bioscientifica Ltd. 